\title{
Acute Appendicitis in the Public and Private Sectors in Cape Town, South Africa
}

\author{
Dr. Estin Yang
}

YNGEST001

Thesis submitted in fulfillment of the requirements for the degree of

\section{Master of Public Health}

Faculty of Sciences

University of Cape Town

2014 
The copyright of this thesis vests in the author. No quotation from it or information derived from it is to be published without full acknowledgement of the source. The thesis is to be used for private study or noncommercial research purposes only.

Published by the University of Cape Town (UCT) in terms of the non-exclusive license granted to UCT by the author. 


\section{DECLARATION}

Acute Appendicitis in the Public and Private Sectors in Cape Town, South Africa Course Code: PPH 7015W

I, Estin Yang (YNGEST001), hereby declare that the dissertation of the above title is my original work (except where acknowledgements indicate otherwise) and that neither the whole work nor any part of it has been, is being, or is to be submitted for another degree in this or any other university.

I empower the university to reproduce for the purpose of research either the whole or any portions of the contents in any manner whatsoever.

This dissertation has been submitted by the author in partial fulfilment of the requirements for the degree of Master of Public Health at the University of Cape Town.

Signature:

Date: 


\section{THESIS ABSTRACT}

Background: Acute appendicitis is one of the commonest surgical emergencies in the developed world. It naturally progresses to perforation if left untreated, which is a potentially life-threatening condition. Surgical removal of the appendix is the definitive cure, and timely treatment avoids preventable morbidity and mortality. Compared to the Western world, the incidence of appendicitis is relatively low in South Africa, but with higher complication and rupture rates. Although there have been numerous studies published on appendicitis in South Africa, the literature is notably missing outcome data in the private sector. Therefore, this study aims to compare acute appendicitis in the public and private sectors in Cape Town, exploring patient characteristics, perforation rates, outcomes, and return to work.

Methods: A structured literature review was performed on all published studies researching appendicitis in South Africa. Historical research trends, perforation rates, and other relevant outcomes were analysed.

A prospective audit was performed for patients undergoing appendicectomy for acute appendicitis at two public and three private hospitals in Cape Town. Hospital records were reviewed, including vital data, operative notes, and histology results. Patients were interviewed during their hospitalisation and four weeks later, exploring their journey of care. Perforation rates and other relevant outcomes were compared between the public and private sector cohorts.

Results: Overall, 134 patients were enrolled, with 73 from the public sector and 61 from the private. Education and employment were higher among private sector patients. Public sector patients had a higher perforation rate $(30.6 \%$ vs $13.2 \%, \mathrm{p}=0.023)$. Times to presentation were not statistically different between the two groups. Public patients had longer hospital stays (5.3 vs 2.9 days, $\mathrm{p}=0.036$ ) and longer return to work times ( 23.0 vs 12.1 days, 
$\mathrm{p}<0.0001)$. Although complication rates were similar, complications in public hospitals were more severe.

Discussion: Public sector patients with appendicitis had higher rupture rates, worse complications, and longer hospital stays than private sector patients. This disparity likely stems from a combination of social and economic differences that characterise the patient populations that are served in each sector. Private sector patients have rupture rates similar to developed nations. Further research is needed to identify and address factors that influence health-seeking behaviours among public sector patients, to strengthen the health system and improve appendicitis outcomes. 


\section{ACKNOWLEDGMENTS}

Many thanks to Professors Delawir Kahn (Department of Surgery, UCT) and Colin Cook

(Division of Ophthalmology, UCT) for their supervision and guidance over this study, as well as through the finalisation of this manuscript.

Acknowledgment also goes to Dr. Robert Baigrie (Matley \& Partners, Department of Surgery, UCT), Dr. Juan Klopper (Department of Surgery, UCT), Dr. Francois Malherbe (New Somerset Hospital), Dr. Colin McGuire (Kingsbury Hospital), and Dr. Ian Marr (Kingsbury Hospital) for their assistance in facilitating data collection for this research. 


\section{TABLE OF CONTENTS}

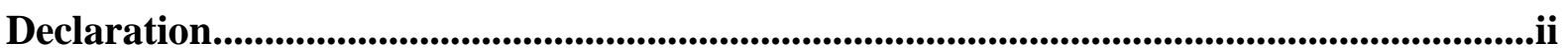

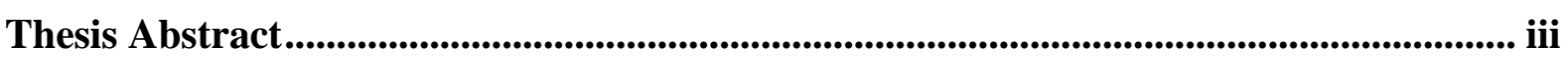

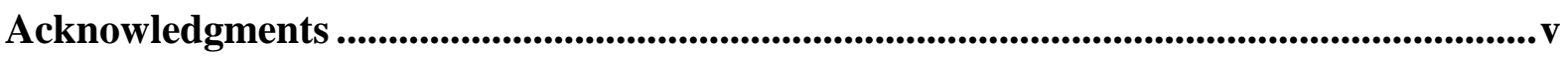

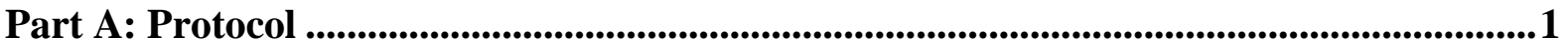

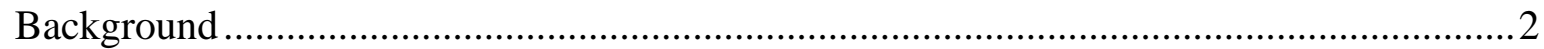

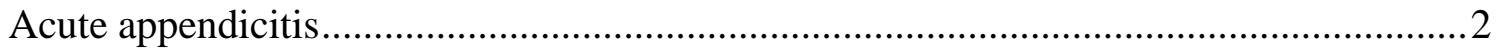

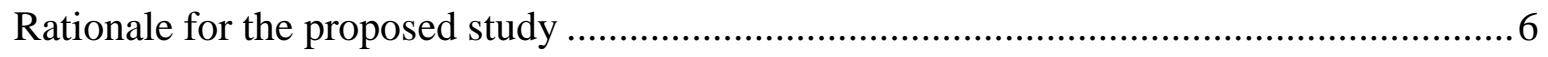

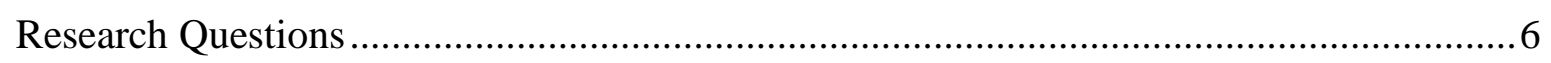

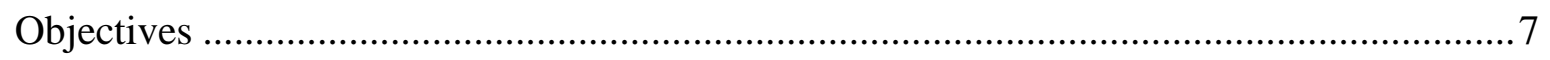

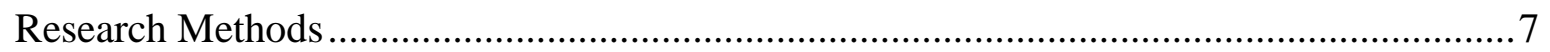

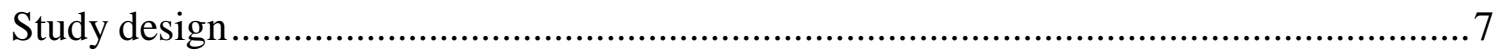

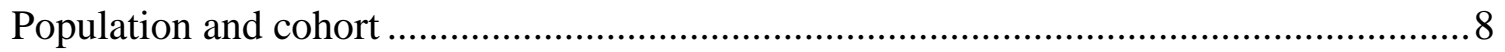

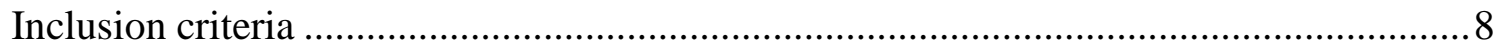

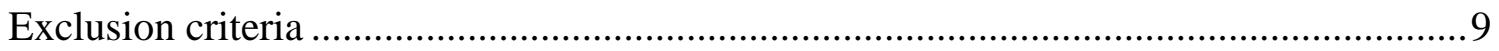

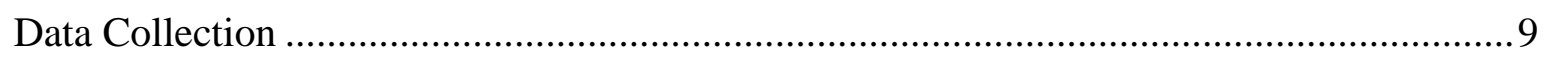

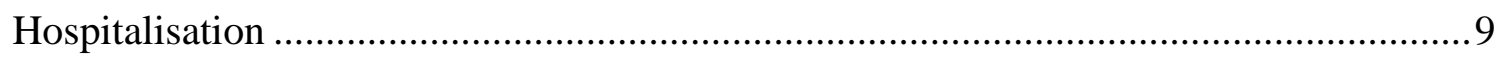

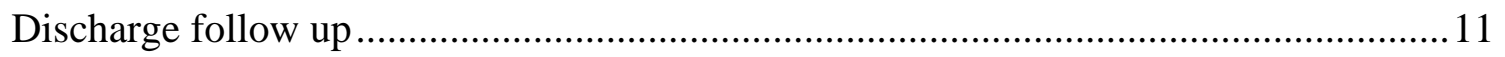

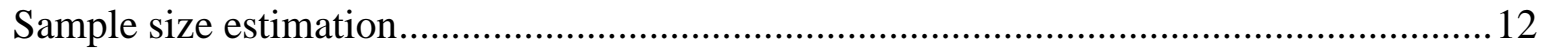

Estimated sample size for two-sample comparison of proportions: ............................. 13

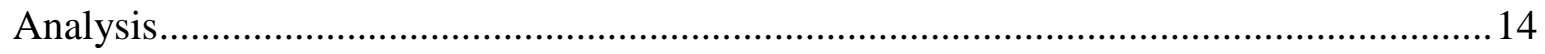

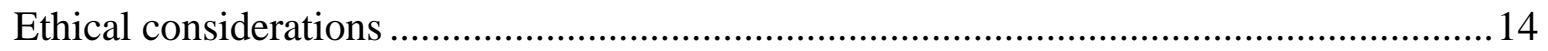

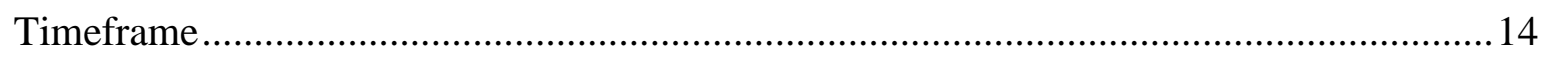

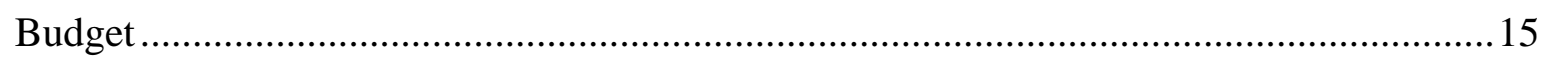

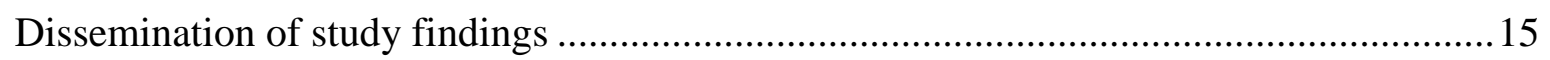

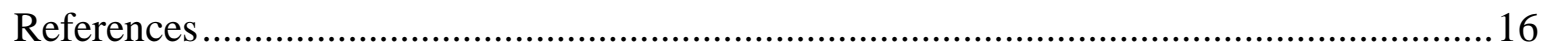

Part B: Literature Review ...............................................................................................................1

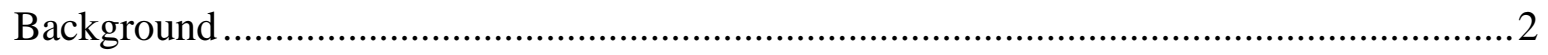

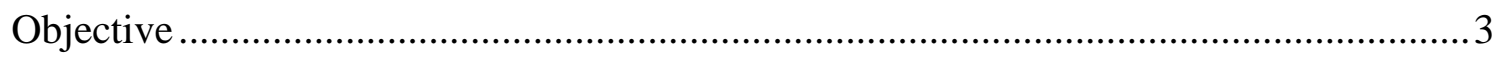

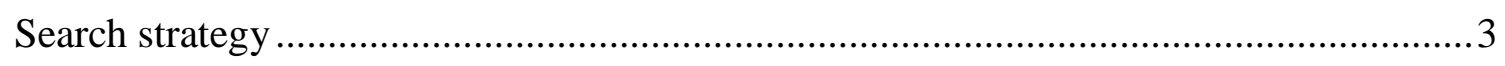

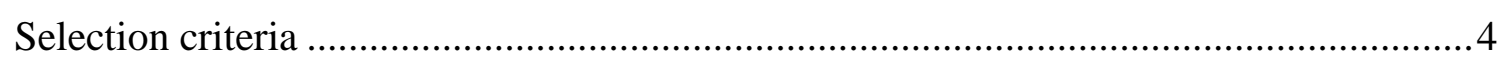

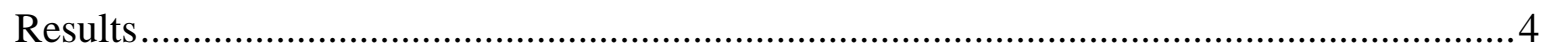

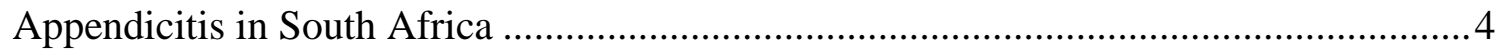

Differential incidence - dietary hypothesis \& fibre intake ...........................................

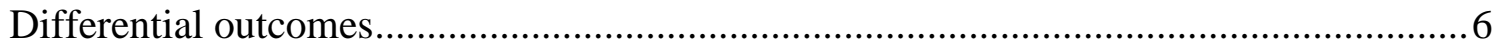




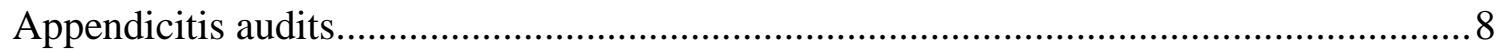

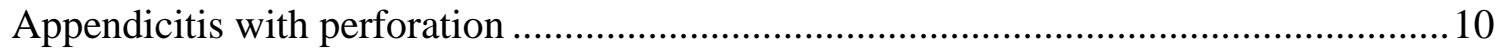

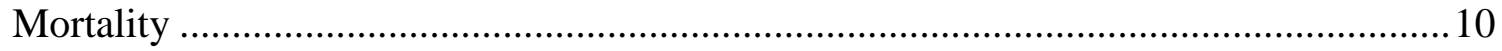

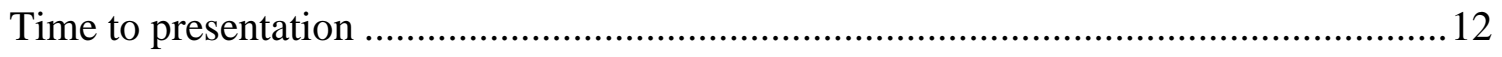

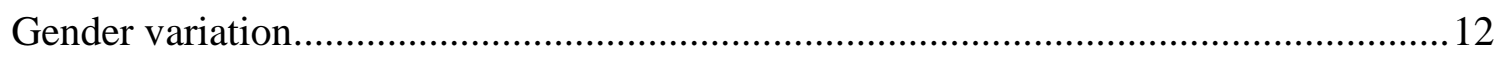

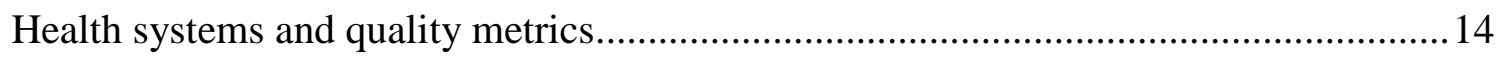

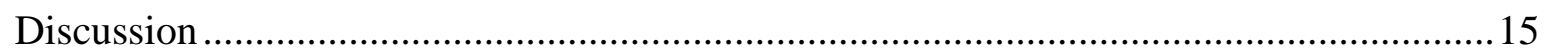

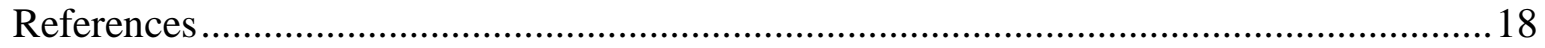

Part C: Manuscript .........................................................................................................................1

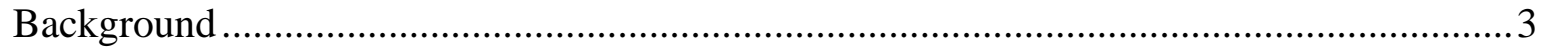

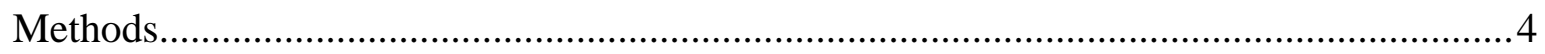

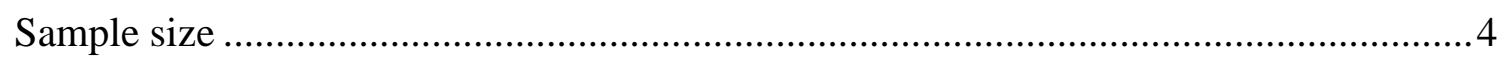

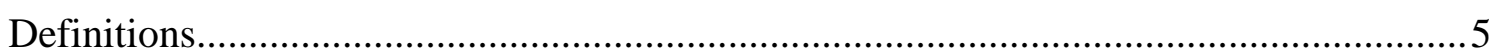

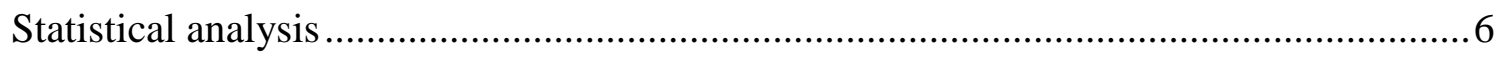

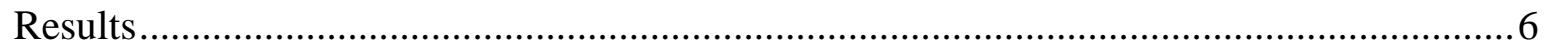

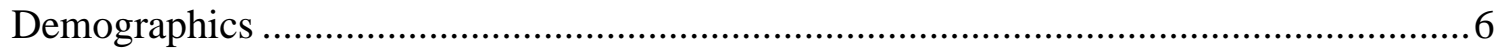

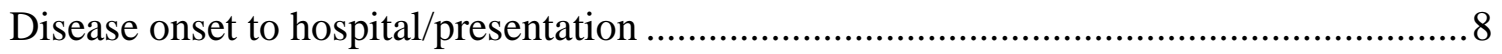

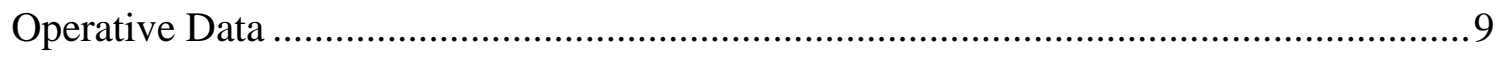

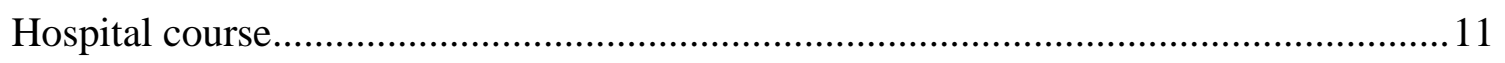

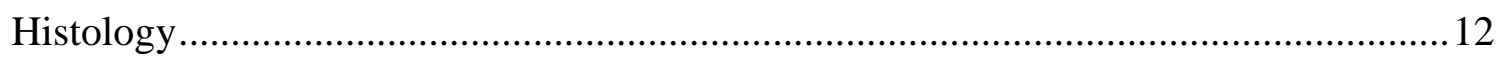

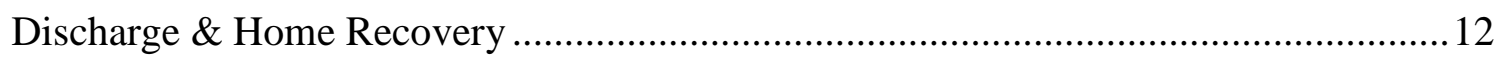

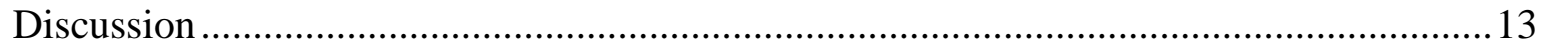

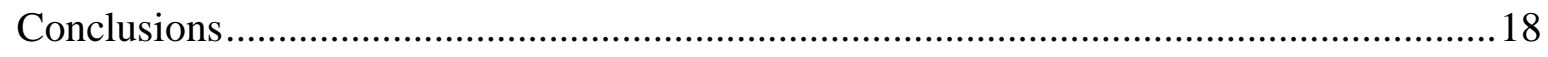

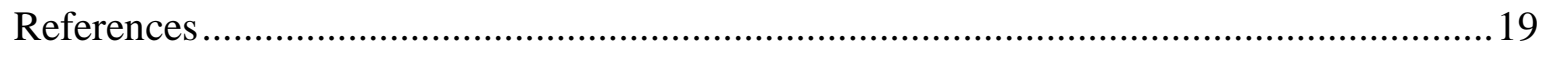

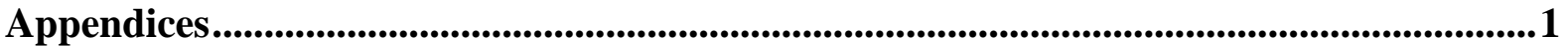

Appendix A: Data Collection Sheet........................................................................ 1

Appendix B: Patient Information Sheet and Consent Form ........................................... 1

Appendix C: Letter of Approval from Research Ethics Committee .................................... 4

Appendix D: Instructions for Authors (JAMA Surgery) ....................................................5 


\section{LIST OF TABLES}

Part A: Protocol .1

Table 1. Ruptured appendicitis in South Africa ....................................................... 13

Table 2. Ruptured appendicitis in the United States ................................................ 13

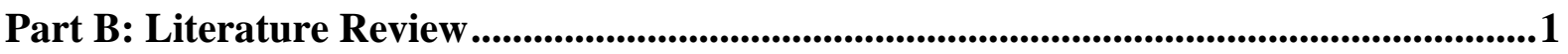

Table 1. Audits for patients undergoing appendicectomy for presumed acute

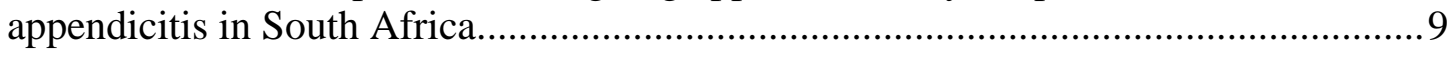

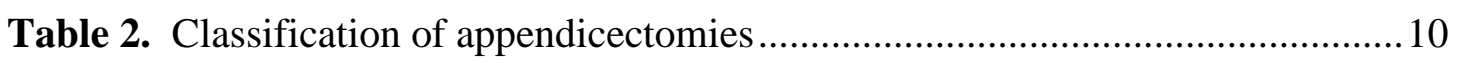

Table 3. Mortality for patients undergoing appendicectomy .................................. 11

Table 4. Time to presentation for acute and perforated appendicitis ......................... 12

Table 5. Normal appendices by gender ................................................................ 13

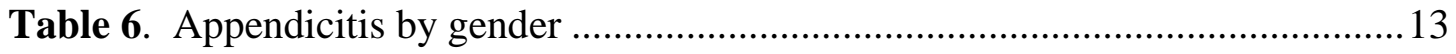

Table 7. Ruptured appendices by gender .......................................................... 14

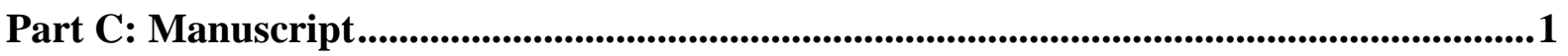

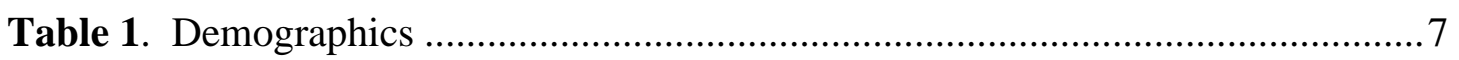

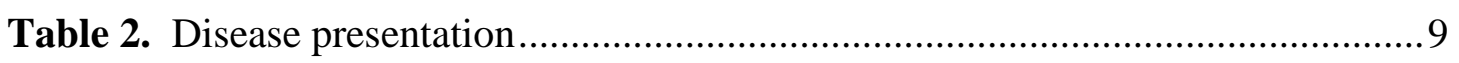

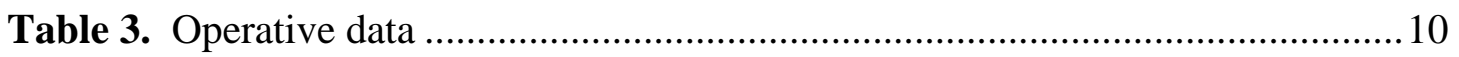

Table 4. Hospital course and complications.......................................................... 11

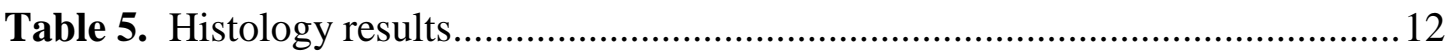

Table 6. Return to work by histologic diagnosis................................................ 13 


\section{PART A: PROTOCOL}




\section{A prospective analysis of the journey of care for patients undergoing appendicectomy in the public and private sectors in Cape Town}

$\underline{\text { Principal Investigator }}$

Estin Yang, MD

Masters in Public Health candidate, University of Cape Town

Resident Physician, Department of Surgery, Oregon Health and

Sciences University

\section{$\underline{\text { Research Supervisors }}$}

Colin Cook, MBChB, FCOphth(SA), FRCOphth, MPH

Delawir Kahn, ChM, FCS(SA)
Professor, Mauerberger Chair of Ophthalmology, Division of Ophthalmology, University of Cape Town

Professor, Head of Department, Department of General Surgery, University of Cape Town

\section{Background}

\section{Acute appendicitis}

Appendicitis is one of the commonest surgical emergencies in the developed world ${ }^{1}$. While its aetiology is still a matter of debate ${ }^{2}$, there are no known environmental or biological risk factors for developing the disease. In its disease course, the appendix initially becomes inflamed and quickly progresses to perforation, leading to soiling of the abdominal cavity, sepsis, and potentially death ${ }^{3}$. Although there is some advocacy for antibiotics as a first-line therapy ${ }^{4}$, the accepted, definitive cure for the disease is surgical removal of the appendix through appendicectomy. With a consistent, time-dependent progression, timely surgical care is therefore critical in minimising adverse outcomes from this disease.

Appendicular perforation is considered the natural progression of acute appendicitis, and carries a much heavier disease burden to the patient, in addition to posing a significant 
resource burden to the health system. Patients who progress to perforation have longer hospital stays, higher mortality, and higher complication rates than those with non-perforated appendicitis $^{5}$. As such, they present a higher economic burden to the healthcare system from what may be seen as a preventable condition. Thus, considering these dramatic differences in outcomes for perforated and non-perforated patients as well as the time-dependent nature of the disease, perforated appendicitis has been used as a measure of health care access and equity for numerous public health studies in the U.S. ${ }^{6,7}$.

Statistically, perforation rates are higher among the young, elderly, and men ${ }^{8}$. It has also been found to correlate with health insurance status ${ }^{9-11}$, poor utilisation of preventive health services $^{10}$, race ${ }^{11-13}$, and mental disease ${ }^{14}$. Most importantly, however, is the risk of perforation resulting from a delay in appropriate surgical care.

Delays in receiving timely surgical care can result from a multitude of issues, all leading to increased perforation rates. Patients are more likely to perforate if they do not present to the hospital promptly ${ }^{15,16}$, but even when they do, late diagnoses by medical professionals may also lead to delayed surgery and therefore potential rupture ${ }^{17,18}$. Even once patients are hospitalised, significant in-hospital delays increase risk of perforation ${ }^{19-21}$. Thus, every effort must be made to have patients diagnosed correctly and undergo treatment in an expeditious manner.

\section{Appendicitis in South Africa}

The prevalence of both acute and ruptured appendicitis are notably different between the developed and developing world. Epidemiologic studies in the U.S. estimate an annual incidence of appendicitis at 110 per $100,000^{8}$, with several studies conducted in Europe 
producing incidence estimates in similar ranges ${ }^{2,22}$. In contrast to the high prevalence of disease in these developed nations, rural Africans have been found to have a much lower annual incidence, as low as 3.5 per 100,000 for rural Africans in South Natal ${ }^{23}$, with more recent estimates rising to 15 per $100,000^{5,24}$. Despite clear differences in incidence between various populations, the risk factors that contribute to these differences are still uncertain, although variation in diet and dietary fibre intake are strongly thought to be contributory ${ }^{2}$. Although the overall rates of appendicitis are relatively low in South Africa, the rates of ruptured appendicitis are notably higher, compared to Western nations. Estimated rates of perforation range from $16-30 \%$ in the U.S. ${ }^{8,15,19}$, compared to $34-57 \%$ in South Africa ${ }^{5,24,25}$. Assuming that the pathogenesis of disease and natural progression to perforation are similar among the two populations ${ }^{25}$, these higher perforation rates may be attributable to longer times to presentation for South Africans.

The median time for presentation for patients with rupture in the U.S. was 57.2 hours, as compared to 24 hours for non-ruptured patients ${ }^{15}$. In a study conducted in Ireland, average times to presentation was 38.1 hours (median 24 hours), with perforated patients presenting an average of 62.1 hours after symptom onset ${ }^{16}$. In South Africa, however, patients with appendicitis have been shown to present an average 88.8 hours after symptom onset, 64.8 hours for non-ruptured patients and 105.6 for ruptured patients ${ }^{24}$. A separate study found time from symptom onset to hospital presentation to be an average of 81.6 hours for South Africans in Durban - 57.6 versus 91.2 hours for non-ruptured and ruptured patients ${ }^{5}$.

According to the above observations, patients studied in South African audits clearly have longer times to present to the medical system from symptom onset and markedly higher perforation rates. Why is this the case? Studies have indicated that South African patients face unique barriers to medical care, particularly for poor and rural South Africans. 
Transport times are longer for patients who present from rural locations ${ }^{5}$, as well as for blacks and coloured patients. The costs of transport, even separate from the cost of medical care itself, can be unaffordable and therefore prohibitive for seeking medical care - almost $20 \%$ of the poorest South Africans found that the cost of transportation to a medical facility was catastrophic ${ }^{26}$.

Patients also fear disrespectful treatment at medical facilities, although this perception is held more strongly by patients who have yet to be hospitalised ${ }^{26}$. Additionally, many South African patients do not always follow the "classic" symptomatology of acute appendicitis, leading to delays in diagnosis ${ }^{5,24}$. Together, these factors may deter patients from seeking medical care in a timely fashion, which is critical in catching the disease in an early state to avoid perforation. While there have been studies investigating general factors that affect health-seeking behaviours ${ }^{26}$, research specifically describing the journey of care for appendicitis patients is notably missing.

Additionally, there is a lack of data regarding recovery at home for South African surgical patients. U.S. studies have estimated that patients take approximately 25 days to return to work after open appendicectomy ${ }^{27}$, which is the predominant operation performed in South Africa for appendicitis ${ }^{5,24}$, but there is no data regarding return to work for South Africans recovering from appendicectomy. These recovery times may be similar to those of the Americans, but considering the significant differences in time in seeking care, they could very well be different. Given the complex network of cultural and social factors that affect the timeliness with which South Africans seek medical care, these same factors may affect their recovery upon their discharge from the hospital.

Much of the current South African appendicitis literature is limited to the public sector. There is virtually no data from private sector patients, and it is unclear if private sector 
patients face similar outcomes and exhibit similar health-seeking behaviours as patients in the public sector.

In keeping with the posed question and its context, the aims of this study are three-fold: investigate the factors that contribute to delays in seeking care, compare outcomes, and estimate the recovery time for appendicectomy patients in the public and private sectors.

\section{$\underline{\text { Rationale for the proposed study }}$}

South African patients with appendicitis present later than Western patients, with consequently higher perforation rates. There is little data on private sector patients with appendicitis in South Africa, although it is often assumed they behave similarly to patients in developed countries. This study aims to compare the overall appendicitis experience between public and private sector patients in South Africa. Much of the current literature is limited to public sector patients, and there is little research exploring pre- and post-hospitalisation experiences for surgical patients in either sector. Therefore, this prospective study aims to explore differences between patients in the two sectors, both with qualitative analyses of preand post-hospitalisation journeys, as well as quantitative comparisons of clinical outcomes and rupture rates. This information will allow for a broader understanding of patients' experiences in both sectors, as well as provide insight into potential system strengthening opportunities.

\section{$\underline{\text { Research Questions }}$}

1. How do patient demographics and characteristics differ between public and private sector patients undergoing appendicectomy? 
2. Are appendicular perforation rates in the public sector similar to perforation rates in the private sector?

3. What are the factors that contribute to delays in care for public and private sector patients with acute appendicitis? How do they differ between the two sectors?

4. What are the return to work times for public and private sector patients undergoing appendicectomy, and what factors influence their recovery?

\section{$\underline{\text { Objectives }}$}

1. To compare patient demographics and characteristics of private and public sector appendicectomy patients.

2. To compare appendicitis outcomes between private and public sector patients in Cape Town, including perforation rates, operative findings, histology results, complications, and mortality.

3. To compare pre-hospital journeys of private and public sector patients, exploring referral patterns and factors that contribute to delays in care.

4. To compare post-hospital recovery for private and public sector patients, and to estimate return to work times.

\section{$\underline{\text { Research Methods }}$}

\section{Study design}

A prospective cohort study design will be employed to investigate patients who undergo primary appendicectomy for acute appendicitis. Patients will be enrolled at several public and private hospitals in the Cape Town metropole. During the study period, all patients who 
meet inclusion criteria will be offered enrolment into the study. A researcher will meet briefly with them during their hospitalisation to discuss enrolment, and a post-discharge follow-up interview session will be scheduled at hospital discharge. Patient data will be collected from hospital charts and operative records and inputted into a secure database.

An interview, held either on the phone or in person, will be conducted with each study participant 3-4 weeks after hospital discharge. This interview will explore their postdischarge recovery, return to work, and reflect on their time of illness prior to hospitalisation.

\section{Population and cohort}

The sample is designed to represent adult patients with acute appendicitis in Cape Town. The cohorts will be defined as patients undergoing appendicectomy at either a public or private sector hospital.

\section{Inclusion criteria}

- Patients undergoing primary appendicectomy for a diagnosis of acute appendicitis, with or without rupture. The operations include either laparoscopic or open appendicectomy, as well as other surgical interventions for late-presenting appendicitis. These latter cases will be reviewed on a case-by-case basis.

- Preoperative diagnosis of appendicitis, whether early or ruptured, or intraabdominal sepsis secondary to appendicitis.

- Adult patients, 18 years of age and older 


\section{Exclusion criteria}

- Patients undergoing incidental appendicectomy while undergoing a separate surgical procedure.

- Patients diagnosed with appendicitis who are treated nonoperatively.

- Patients taken to the operating room for presumed appendicitis but who are found intraoperatively to have a different pathology and do not undergo appendicectomy

\section{$\underline{\text { Data Collection }}$}

\section{Hospitalisation}

A trained investigator will review the patient's hospital records for the following data.

Patients will be enrolled and consent obtained. The patient will be interviewed about their pre-hospital experience.

- Demographics

$\bigcirc$ Age, gender, race

○ Address \& postal code

- Highest level of education

- Employment, Estimated income

- Presentation

○ Time of symptom onset

○ Referral process, if applicable

- Means of getting to the hospital

- Diagnostic workup:

○ Presenting symptoms 
- Right lower quadrant or periumbilical pain

- Nausea/emesis

- Diarrhea

- Anorexia

- Fever

- Clinical history and physical exam

- History of intraabdominal surgery

- History of abdominal pain

- Smoking, HIV, other comorbid diseases

- Vital signs and physical exam

- BMI

○ Laboratory investigations

$\bigcirc$ Imaging usage and results

- Operative management \& findings

○ Time to operation from admission

$\circ$ Length of operation (anaesthetic time)

○ Surgical approach

O Operative diagnosis and findings

- Postoperative management
- Length of hospital stay
○ In-hospital complications
○ Family visitors 


\section{Discharge follow up}

The following are general topics that will be covered in semi-structured interviews with study patients during their follow up phone calls and final interviews. The interview will be conducted 3-4 weeks after discharge, either telephonically or in person at a follow-up clinic.

- Postoperative recovery

○ Return to work

- When did the patient return to work, if they have already?

- If unemployed, then how long did it take for the patient to return to a regular level of activity?

- Support structures for recovery

- How did the patient return home from the hospital (e.g. private or public transportation)?

- How were the first few days of recovery at home? Were there friends or family present to help you with your recovery?

- What were the most difficult parts of the recovery process?

- How did the illness and hospitalisation affect the patient's life?

- Financial effect

- Did the course of the illness significantly affect the patient's financial situation? What mechanisms were used to pay for the costs of medical care?

- Satisfaction with care

- Was the patient satisfied overall with the surgical and medical care received at the hospital? Why or why not?

- Did the patient feel comfortable and sufficiently knowledgeable to take care of him-/herself once he/she was discharged? Why or why not? 


\section{$\underline{\text { Sample size estimation }}$}

Much of the quantitative outcomes that are being measured are being collected to ensure that our patient sample is similar in characteristics to study populations included in previous studies. The statistical analysis for this study is not designed to detect statistical differences between surgical care provided at private and public hospitals, which we hypothesise should be similar. However, part of our assumptions in this study are that the patient populations served at public and private hospitals are inherently different, with the former serving poorer patients with less medical aid, and the latter serving wealthier patients and perhaps better overall access to care.

Although these populations exist within the same city, the key demographic differences between the two suggest that the public hospital patients may reflect trends for rural Africans, while private hospital patients may then reflect trends for patients in Western nations ${ }^{2}$. Thus, we hypothesise that perforation rates in these two patient populations would then reflect perforation rates in the developed versus the developing world.

In Tables 1 and 2, epidemiologic studies estimate perforation rates to be $47.3 \%$ for South African patients, mainly serving the rural poor, whereas perforation rates in the U.S. average 21.7\%. These reported proportions represent the percentage of patients with ruptured appendicitis among all patients who had appendicitis and underwent appendicectomy, and not the incidence rates of perforated appendicitis in the general population.

If, then, we use the proportions of ruptured appendicitis for South Africa and the United States as expected rates of perforation among the two cohorts in our study, then each cohort arm will respectively need 59 patients to demonstrate this difference with statistical significance, for a total of 118 patients included in the entire study. The level of significance $(\alpha)$ will be set at 0.05 , and the study power $(1-\beta)$ set at 0.80 . 
Table 1. Ruptured appendicitis in South Africa

\begin{tabular}{|l|l|l|l|l|l|}
\hline City & Incidence & Hospital & Study size & Author & Year \\
\hline Pietermaritzburg & $57 \%$ & Edendale & 200 & Kong & 2012 \\
\hline Durban & $34 \%$ & Prince Mshiyeni & 324 & Chamisa & 2009 \\
\hline East London & $51 \%$ & Frere & 436 & Rogers & 2008 \\
\hline
\end{tabular}

Note: Kong/Rogers is based on operative findings, Chamisa is by path report. According to Chamisa, the operative reports actually estimated a lower rate for rupture at $30.5 \%$

Table 2. Ruptured appendicitis in the United States

\begin{tabular}{|l|l|l|l|l|l|}
\hline City & Incidence & Hospital & Study size & Author & Year \\
\hline USA & $30 \%$ & --- & 683590 & Papandria & 2012 \\
\hline New York, USA & $16 \%$ & --- & 219 & Bickell & 2006 \\
\hline USA & $19 \%$ & --- & 8717 & Addis & 1990 \\
\hline
\end{tabular}

Note: Papandria \& Addis are both based on hospital ICD codes, Bickell is based on operative findings

SA average $=47.3 \%$ US average $=21.7 \%$

Estimated sample size for two-sample comparison of proportions:

Test $\mathrm{H}_{0}: \mathbf{p} 1=\mathbf{p} 2$, where $\mathrm{p} 1$ is the proportion in population 1 and $\mathrm{p} 2$ is the proportion in population 2

Assumptions:

$$
\begin{aligned}
\alpha= & 0.0500 \text { (two-sided) } \\
\text { power } & =0.8000 \\
\mathrm{p} 1 & =0.4730 \\
\mathrm{p} 2 & =0.2170 \\
\mathrm{n} 2 / \mathrm{n} 1= & 1.00
\end{aligned}
$$

Estimated required sample sizes:

$$
\begin{aligned}
& \mathrm{n} 1=59 \\
& \mathrm{n} 2=59
\end{aligned}
$$




\section{$\underline{\text { Analysis }}$}

Statistical analysis will be performed using STATA $^{28}$, using appropriate statistical methodology. Interview data will be transcribed and analysed using relevant software.

\section{Ethical considerations}

There are no interventions being proposed through this study, and patient care will not be altered or affected in any way. All identifying data will be kept confidential and no personal information will be published. Identifiers will also be omitted from interview transcriptions. Data analysis will be conducted separately from patient identifiers. Upon the completion of the data analysis and the study, any identifiable patient data will be destroyed.

\section{$\underline{\text { Timeframe }}$}

The project will take place over the course of approximately nine months. The timeframe will be roughly as follows:

- Data collection: 5 months

- Data processing: 1 month

- Data analysis: 1 month

- Manuscript preparation and writing: 2 months 


\section{Budget}

This project has no sponsored industry funding. Hardware and software support will be independently provided. Patient enrolment, interviews, data collection and analysis will be conducted by the research team and funded independently. Patient incentives will be funded through donations.

\section{Dissemination of study findings}

Study findings will be summarised in the manuscript, which will be submitted for review to the UCT MPH Dissertation Committee. Pending this review, the manuscript will then be submitted for publication at an appropriate peer-reviewed medical journal of good repute. 


\section{$\underline{\text { References }}$}

1. Saidi HS, Adwok JA. Acute appendicitis: an overview. East Afr Med J. Mar 2000;77(3):152-156.

2. Walker AR, Segal I. Appendicitis: an African perspective. $J$ R Soc Med. Nov 1995;88(11):616-619.

3. Berry J, Jr., Malt RA. Appendicitis near its centenary. Ann Surg. Nov 1984;200(5):567-575.

4. Hansson J, Korner U, Ludwigs K, Johnsson E, Jonsson C, Lundholm K. Antibiotics as first-line therapy for acute appendicitis: evidence for a change in clinical practice. World journal of surgery. Sep;36(9):2028-2036.

5. Rogers AD, Hampton MI, Bunting M, Atherstone AK. Audit of appendicectomies at Frere Hospital, Eastern Cape. S Afr J Surg. Aug 2008;46(3):74-77.

6. Gadomski A, Jenkins P. Ruptured appendicitis among children as an indicator of access to care. Health Serv Res. Apr 2001;36(1 Pt 1):129-142.

7. Lee SL, Yaghoubian A, Stark R, Shekherdimian S. Equal access to healthcare does not eliminate disparities in the management of adults with appendicitis. The Journal of surgical research. Oct;170(2):209-213.

8. Addiss DG, Shaffer N, Fowler BS, Tauxe RV. The epidemiology of appendicitis and appendectomy in the United States. Am J Epidemiol. Nov 1990;132(5):910-925.

9. Braveman P, Schaaf VM, Egerter S, Bennett T, Schecter W. Insurance-related differences in the risk of ruptured appendix. The New England journal of medicine. Aug 18 1994;331(7):444-449. 
10. Herrod HG, Chang CF. Potentially avoidable pediatric hospitalizations as defined by the Agency for Healthcare Research and Quality: what do they tell us about disparities in child health? Clinical pediatrics. Mar 2008;47(2):128-136.

11. Pieracci FM, Eachempati SR, Barie PS, Callahan MA. Insurance status, but not race, predicts perforation in adult patients with acute appendicitis. Journal of the American College of Surgeons. Sep 2007;205(3):445-452.

12. Smink DS, Fishman SJ, Kleinman K, Finkelstein JA. Effects of race, insurance status, and hospital volume on perforated appendicitis in children. Pediatrics. Apr 2005;115(4):920-925.

13. Guagliardo MF, Teach SJ, Huang ZJ, Chamberlain JM, Joseph JG. Racial and ethnic disparities in pediatric appendicitis rupture rate. Academic emergency medicine : official journal of the Society for Academic Emergency Medicine. Nov 2003;10(11):1218-1227.

14. Tsay JH, Lee CH, Hsu YJ, et al. Disparities in appendicitis rupture rate among mentally ill patients. BMC public health. 2007;7:331.

15. Bickell NA, Aufses AH, Jr., Rojas M, Bodian C. How time affects the risk of rupture in appendicitis. Journal of the American College of Surgeons. Mar 2006;202(3):401406.

16. Kearney D, Cahill RA, O'Brien E, Kirwan WO, Redmond HP. Influence of delays on perforation risk in adults with acute appendicitis. Diseases of the colon and rectum. Dec 2008;51(12):1823-1827.

17. Golladay ES, Sarrett JR. Delayed diagnosis in pediatric appendicitis. Southern medical journal. Jan 1988;81(1):38-42. 
18. Cappendijk VC, Hazebroek FW. The impact of diagnostic delay on the course of acute appendicitis. Archives of disease in childhood. Jul 2000;83(1):64-66.

19. Papandria D, Goldstein SD, Rhee D, et al. Risk of perforation increases with delay in recognition and surgery for acute appendicitis. The Journal of surgical research. Oct 2013;184(2):723-729.

20. Ingraham AM, Cohen ME, Bilimoria KY, et al. Effect of delay to operation on outcomes in adults with acute appendicitis. Archives of surgery (Chicago, Ill. : 1960). Sep 2010;145(9):886-892.

21. Busch M, Gutzwiller FS, Aellig S, Kuettel R, Metzger U, Zingg U. In-hospital delay increases the risk of perforation in adults with appendicitis. World journal of surgery. Jul 2011;35(7):1626-1633.

22. Andersson R, Hugander A, Thulin A, Nystrom PO, Olaison G. Indications for operation in suspected appendicitis and incidence of perforation. BMJ (Clinical research ed.). Jan 8 1994;308(6921):107-110.

23. Walker AR, Walker BF, Manetsi B, Tsotetsi NG, Segal I. Appendicitis in Soweto, South Africa: traditional healers and hospitalization. J R Soc Health. Dec 1989;109(6):190-192.

24. Kong VY, Bulajic B, Allorto NL, Handley J, Clarke DL. Acute appendicitis in a developing country. World journal of surgery. Sep;36(9):2068-2073.

25. Chamisa I. A clinicopathological review of 324 appendices removed for acute appendicitis in Durban, South Africa: a retrospective analysis. Ann R Coll Surg Engl. Nov 2009;91(8):688-692. 
26. Harris B, Goudge J, Ataguba JE, et al. Inequities in access to health care in South Africa. J Public Health Policy.32 Suppl 1:S102-123.

27. Frazee RC, Roberts JW, Symmonds RE, et al. A prospective randomized trial comparing open versus laparoscopic appendectomy. Ann Surg. Jun 1994;219(6):725728; discussion 728-731.

28. StataCorp. Stata Statistical Software: Release 13. College Station, TX: StataCorp LP; 2013. 


\section{PART B: LITERATURE REVIEW}




\section{Background}

Appendicitis is one of most common surgical emergencies in the developed world ${ }^{1}$. In its disease course, the appendix becomes inflamed and swollen as intestinal bacteria multiply in the lumen, recruiting white blood cells and forming pus. With this accumulation of purulent material, intraluminal pressure rises and leads to wall ischemia, necrosis, and eventual rupture. Rupture can then either lead to a contained abscess or widespread soiling of the abdominal cavity, which in turn causes sepsis and potentially death ${ }^{2}$.

The aetiology of appendicitis is generally thought to be obstruction of the appendicular lumen, which facilitates intraluminal pressure build-up. However, this is contested as obstruction itself does not guarantee disease, and other theories of disease have been supported ${ }^{3}$. Although its aetiology is still a matter of debate, appendicitis affects both men and women, young and old, and people of all races ${ }^{3}$. Despite this widespread potential, its incidence peaks in children and young adults, and is more common in developed regions over developing regions ${ }^{4}$.

If left untreated, acute appendicitis naturally progresses to rupture, causing longer hospital stays, higher complication and mortality rates ${ }^{5}$. A ruptured appendix carries a heavier disease burden to the patient and resource burden to the health system ${ }^{6}$.

In particular, rupture rates have been found to be higher among men, the elderly and the very young ${ }^{7}$. It has also been found to correlate with health insurance status ${ }^{8-10}$, poor utilisation of preventive health services ${ }^{11}$, race ${ }^{12,13}$, and mental disease ${ }^{13}$. For each of these risk factors, increased perforation risk is essentially attributable to delayed medical care.

There is some advocacy for antibiotics as a first-line therapy ${ }^{14}$, but the accepted, definitive cure for the disease is surgical removal of the appendix via appendicectomy ${ }^{15}$. Considering 
the time-dependent nature of the disease, timely surgical care is critical in minimising adverse outcomes and disease burden. Thus, considering these dramatic differences in outcomes for ruptured and non-ruptured patients as well as the time-dependent nature of the disease, ruptured appendicitis has been used as a measure of health care access and equity for numerous public health studies ${ }^{16}$.

However, much of the research investigating risk factors for perforation has been conducted in the U.S. and European countries. As South Africa has a political and a social history, a health system structure, and population demography which are unique from these other settings, the generalisability of these studies may be somewhat limited to our country. Therefore, a structured review was conducted on appendicitis research in South Africa in order to better understand the nature of appendicitis and risk factors for perforation in this setting.

\section{Objective}

The objective of this structured literature review is to provide a historical and contemporary perspective of appendicitis in South Africa.

\section{Search strategy}

MEDLINE and EBM Reviews were searched for published literature on appendicitis and appendicectomy in South Africa. The reference lists of identified studies were searched further to identify relevant studies. Articles which were published in Afrikaans were translated into English for review. For all searches, the following specific search terms were used: 
1. "Appendicitis AND South Africa"

2. "Appendectomy AND South Africa"

3. "Appendicectomy AND South Africa"

\section{Selection criteria}

All peer-reviewed, published, original research studies addressing appendicitis in South Africa were eligible for inclusion in this review. For appendicitis and appendicectomy audits, inclusion criteria and methodology for defining appendicitis were used in determining inclusion in analysis. Recurring themes and observations by researchers were compiled and assessed.

\section{$\underline{\text { Results }}$}

\section{Appendicitis in South Africa}

The first audit for appendicitis in South Africa was published in 1939, drawing from hospital records throughout the country in an effort to assess the nature of the disease and its impact on different racial groups ${ }^{17}$. When contrasting the disease between ethnic groups, Erasmus formed two major conclusions, namely, that white patients had significantly higher incidence rates of appendicitis than black patients, but with significantly less morbidity and mortality ${ }^{17}$. These two observations formed the groundwork and direction for further study of appendicitis in South Africa over the next 70 years. 


\section{Differential incidence - dietary hypothesis \& fibre intake}

In Erasmus's study, hospital records from three Johannesburg hospitals were reviewed from the years 1929-1937, with appendicitis and overall admissions recorded according to racial groups. Using these figures, $3.56 \%$ of white inpatients were admitted for appendicitis, compared to $0.81 \%$ of coloureds and $0.41 \%$ of black inpatients ${ }^{17}$. Although these figures do not represent the true incidence rates in the general population, as hospital access and utilisation patterns likely differed between racial groups, the important possibility of differential incidences between racial groups was raised. These trends were supported by findings from audits in Cape Town and Upington, respectively ${ }^{18,19}$.

A leading theory explaining these differences posited that Westernised diets with declining dietary fibre content increased the risk for developing appendicitis ${ }^{20}$. Consistent with this reasoning, Erasmus noted that appendicitis was more common among black South Africans on "European" diets than those on "native" diets ${ }^{17}$, suggesting that environmental factors influenced the pathology of appendicitis in addition to genetic proclivities for disease. This association has been supported through further ecological studies, evaluating the epidemiology of these diseases in comparison to dietary habits in both developed and developing countries around the world ${ }^{21}$.

Burkitt et al $^{21}$, studied the dietary fibre content and stool transit times among people in the United Kingdom, Uganda, and South Africa, finding a negative correlation between fibre content and transit times, irrespective of ethnicity. Looking specifically at the South African subjects in this study - white students eating a refined diet, black students on mixed diets, and black students on unrefined diets - this correlation still held true, with longer stool transit times as fibre content decreased. In their study, no community with high-fibre diets had high bowel disease rates, supporting the appendicitis incidence findings previously mentioned. 
For the South African students in particular, dietary fibre consumption negatively correlated with appendicectomy frequency ${ }^{22}$.

If, then, dietary habits dictate risk for appendicitis, it would follow that urbanised communities with increasingly Westernised food consumption would see rises in incidence. Mixed results were seen in South Africa from 1950-1978, as appendicitis rates increased among urban black patients near Durban ${ }^{23}$, but with no changes noted among semirural black patients near Bloemfontein ${ }^{24}$. Furthermore, appendicitis rates among urban black patients near Johannesburg from 1979-1983 were found to be roughly the same as those by Erasmus in $1937^{25}$. However, incidence estimates in South Africa increased from 8.2 cases per 100,000 population in $1986^{25}$ to 15 per 100,000 over twenty years later ${ }^{5,26}$.

Further exploring the dietary hypothesis, there have been several studies investigating the potential causal role of faecaliths, with the thought that greater faecal residue associated with low fibre diets may lead to obstructive faecaliths that in turn cause appendicitis. Black South Africans with appendicitis were more likely to have appendicular faecaliths than those with normal appendices, and as a whole had fewer faecaliths than a comparison group of Canadian patients ${ }^{27}$. These findings were contested at the time ${ }^{28}$, but gathered support years later ${ }^{29}$.

\section{Differential outcomes}

The second main observation from Erasmus's study is that of differential outcomes and mortality rates between black and white South Africans with appendicitis. Blacks not only had higher rates of rupture and complicated appendicitis, their mortality was three times that of whites $-29.81 \%$ vs $9.88 \%{ }^{17}$. These figures echoed previous research done in the United States, when comparing appendicitis outcomes between African-Americans and CaucasianAmericans in New Orleans ${ }^{30}$. While Erasmus suggested that a biological mechanism may 
contribute to these worse outcomes for blacks, the difference in outcome seemed to relate more to health-seeking behaviours that affected how promptly medical care was received.

A recurring theme when discussing the high perforation rates in South Africa is delayed presentation. Several studies found that perforated patients generally delayed care longer than those with non-perforated appendicitis ${ }^{5,29} 31$, and that South Africans as a whole presented later than patients in developed countries, leading to higher perforation rates ${ }^{26}$. In trying to understand the reasons underlying this phenomenon, authors cited socioeconomic disadvantage ${ }^{26}$, health system weaknesses ${ }^{5}$, poor access to care ${ }^{29}$, use of traditional healers ${ }^{32}$, and poor education ${ }^{33}$. Only one study contested the association between delayed presentation and perforation, as delays were similar among both patient groups ${ }^{34}$. In their audit in East London, Kong et al (2013) identified rural origin as an independent risk factor for perforation ${ }^{35}$.

Even if patients do present to health facilities in a timely fashion, misdiagnoses can delay surgical treatment. As acute appendicitis is mostly a clinical diagnosis, the question of whether disease presentation varies between races has been contested over the years. Some have argued that blacks generally have atypical disease presentations which diverge from "classical" appendicitis, thus leading to delayed diagnoses and care ${ }^{5,34}$. Others have argued the opposite, that black Africans with appendicitis present similarly to white Europeans, but barriers in communication and language lead to perceived differences in symptomatology 29,36 


\section{Appendicitis audits}

Ten studies were included for analysis based on inclusion criteria. All included patients undergoing operation for presumed acute appendicitis, and excluded patients undergoing incidental appendicectomy, patients with appendicitis who were treated conservatively without an operation, and patients with chronic appendicitis. For all studies, appendicitis was defined histologically, except for Rogers ${ }^{5}$ and Kong ${ }^{26}$, in which diagnoses were made by operative findings.

Older studies in this review discussed the diagnosis of chronic appendicitis, a diagnosis which often led to negative appendicectomies and persistent symptoms after operation ${ }^{18}$. As a separate and distinct preoperative entity than acute appendicitis, chronic appendicitis patients were also excluded from analysis.

Studies with different inclusion criteria were excluded from analysis. Moore ${ }^{37}$ and Segal ${ }^{25}$ studied patients with histologically proven appendicitis, thus excluding those with presumed appendicitis who had histologically normal appendices. Movsowitz ${ }^{19}$ audited appendicectomy cases in Upington, but was unclear in his inclusion criteria and had an unusually high number of normal specimens, prompting exclusion from this analysis.

Table 1 summarises the findings from these studies. Of the patients undergoing appendicectomy for presumed acute appendicitis in South Africa, 78.74\% were found to have appendicitis. This figure includes those with perforated appendicitis. Negative appendicectomies constituted $17.29 \%$ of the total operations, and $3.97 \%$ of the operations were found to have appendices diseased with some other pathology. After excluding Muthuphei et $\mathrm{al}^{38}$, who did not report deaths in their study, the overall mortality rate for appendicectomy patients is calculated to be $1.22 \%(36 / 2946)$. 
Table 1. Audits for patients undergoing appendicectomy for presumed acute appendicitis in South Africa

\begin{tabular}{|c|c|c|c|c|c|c|c|c|c|c|c|c|c|}
\hline Author & Year & City of Study & Province* & Study period & $\begin{array}{l}\text { Age } \\
\text { Criteria }\end{array}$ & Race† & $\mathrm{N}$ & M & $\mathrm{F}$ & Normal & Appendicitis & Other & Death \\
\hline Silber & 1953 & Cape Town & $\mathrm{WC}$ & 11 months in 1952 & All & $\mathrm{BCW}$ & 107 & 57 & 50 & 36 & 61 & 10 & 1 \\
\hline Spitz & 1969 & Johannesburg & GP & 1959-1969 & $>14$ & $\mathrm{~W}$ & 666 & 348 & 318 & 210 & 456 & 0 & 3 \\
\hline $\mathrm{Nel}$ & 1979 & Bloemfontein & FS & Jul 1975 - Sep 1978 & All & B & 234 & 169 & 83 & 34 & 187 & 13 & 5 \\
\hline Fulton & 1995 & Mdantsane & $\mathrm{EC}$ & Oct 1991 - Nov 1992 & All & $\mathrm{B}$ & 122 & 72 & 50 & 18 & 96 & 8 & 1 \\
\hline Levy & 1997 & Soweto & GP & Jan 1992 - Jan 1995 & $>14$ & B & 212 & 143 & 69 & 44 & 168 & 0 & 3 \\
\hline Muthuphei & 1998 & Ga-Rankuwa & GP & Jan 1993 - Dec 1995 & All & $\mathrm{B}$ & 408 & 258 & 150 & 60 & 268 & 80 & NA \\
\hline Madiba & 1998 & Durban & KZN & Jan 1990 - Dec 1994 & All & B & 645 & 402 & 243 & 56 & 578 & 11 & 11 \\
\hline Rogers & 2008 & East London & $\mathrm{EC}$ & Sep 2003 - Nov 2005 & All & NA & 436 & 204 & 196 & 52 & 384 & 0 & 4 \\
\hline Chamisa & 2009 & Durban South & KZN & Jan 2002 - Dec 2004 & All & NA & 324 & 254 & 70 & 55 & 258 & 11 & 4 \\
\hline Kong & 2012 & Pietermaritzburg & KZN & Sep 2010 - Sep 2011 & NA & NA & 200 & 128 & 72 & 15 & 185 & 0 & 4 \\
\hline Totals & & & & & & & 3354 & 2035 & 1301 & 580 & 2641 & 133 & 36 \\
\hline
\end{tabular}




\section{Appendicitis with perforation}

Nine audits were included for analysis, based on the criteria mentioned above. Spitz ${ }^{39}$ was excluded, as detailed breakdowns of acute versus perforated patients were not recorded in his article. From the included studies, the perforation rate for patients undergoing appendicectomy for acute appendicitis in South Africa was $36.1 \%$. The negative appendicectomy rate was $13.8 \%$.

Moore ${ }^{37}$ conducted an audit on histologically-proven appendicitis in paediatric patients near Cape Town. Of the 436 proven appendicitis cases which he reviewed, 203 (46.6\%) were perforated, a figure consistent with the findings from the included studies when normal and non-appendicitis cases are removed from analysis.

Table 2. Classification of appendicectomies

\begin{tabular}{ccccccc}
\hline Author & Year & N & Normal & Acute & Perforated & Other Path \\
\hline Silber & 1953 & 107 & 36 & 54 & 7 & 10 \\
Nel & 1979 & 234 & 34 & 127 & 60 & 13 \\
Fulton & 1995 & 122 & 18 & 63 & 33 & 8 \\
Levy & 1997 & 212 & 44 & 122 & 46 & 0 \\
Muthuphei & 1998 & 408 & 60 & 197 & 71 & 80 \\
Madiba & 1998 & 645 & 56 & 272 & 306 & 11 \\
Rogers & 2008 & 436 & 52 & 161 & 223 & 0 \\
Chamisa & 2009 & 324 & 55 & 148 & 110 & 11 \\
Kong & 2012 & 200 & 15 & 71 & 114 & 0 \\
\hline Totals & & 2688 & 370 & 1215 & 970 & 133 \\
\hline
\end{tabular}

\section{Mortality}

Of the audits included for analysis in analysing appendicitis rates, 9 were analysed for mortality. Muthumphei et al ${ }^{38}$ were excluded as deaths were not reported. A summary of appendicular pathology for those patients who died is provided in Table 3. 
Of the 36 recorded deaths, $89.9 \%$ were noted to have appendicitis with perforation and/or generalised peritonitis (32/36). Of the remaining four patients, one was acutely inflamed but with distant abscesses, one had a normal appendix, and there was no mention of surgical findings for the other two.

To compare the mortality rate by perforated and not perforated, Spitz ${ }^{39}$ was also excluded as overall breakdown by pathology was not specified. From the remaining 8 studies, there were a total 33 deaths of 2280 appendicectomies. Of those with perforations, $3.23 \%$ died, compared to $0.28 \%$ of those who were not perforated ( $p<0.01$, Fisher's exact test).

Table 3. Mortality for patients undergoing appendicectomy

\begin{tabular}{ccccc}
\hline Author & Year & N & Death & Comment \\
Silber & 1953 & 107 & 1 & 1 acute suppurative appendicitis with liver and \\
cerebral abscesses
\end{tabular}




\section{Time to presentation}

Of the appendicectomy audits, six published details on the time to presentation for patients with proven perforations compared to those with inflamed appendices. Two studies reported the time in hours, whereas the other four reported the time in days (Table 4). Regardless of the time unit used for measurement, those with perforated appendicitis consistently had symptoms for longer before receiving medical care than those with non-ruptured, inflamed appendices.

Table 4. Time to presentation for acute and perforated appendicitis

\begin{tabular}{cccc}
\hline Hours & Year & Acute & Perf \\
\hline Spitz & 1969 & 36.3 & 59.1 \\
Levy & 1997 & $21.8 \pm 10.9$ & $59.4 \pm 25.5$ \\
\hline & Average & 47.2 & 59.25 \\
& & & \\
\hline Days & Year & Acute & Perf \\
\hline Silber & 1953 & 1 & 3 \\
Madiba & 1998 & $3.06 \pm 4.9$ & $3.54 \pm 4.28$ \\
Rogers & 2008 & 2.4 & 3.8 \\
Kong & 2012 & 2.7 & 4.4 \\
\hline & Average & $2.29(54.96 \mathrm{hrs})$ & $3.69(88.4 \mathrm{hrs})$ \\
\hline
\end{tabular}

\section{Gender variation}

From Table 5, patients undergoing appendicectomy for suspected acute appendicitis were more likely to be male than female. However, from the 7 studies which reported gender breakdowns on appendices which were found to be normal, women were found to have a much higher negative appendicectomy rate $-27.92 \%$ of women undergoing appendicectomy were found to actually have a normal appendix, compared to $9.46 \%$ of men $\left(\chi^{2}=162.2\right.$, $\mathrm{p}<0.01)$. 
Table 5. Normal appendices by gender

\begin{tabular}{cccccc} 
& \multicolumn{2}{c}{ Total } & Normal \\
\hline & Year & M & F & M & F \\
\hline Spitz & 1969 & 348 & 318 & 74 & 136 \\
Fulton & 1995 & 72 & 50 & 3 & 15 \\
Levy & 1997 & 143 & 69 & 12 & 32 \\
Muthuphei & 1998 & 258 & 150 & 24 & 36 \\
Madiba & 1998 & 402 & 243 & 19 & 37 \\
Rogers & 2008 & 204 & 196 & 5 & 17 \\
Chamisa & 2009 & 254 & 70 & 22 & 33 \\
\hline Totals & & 1681 & 1096 & 159 & 306 \\
\hline
\end{tabular}

Five studies provided gender breakdowns for those who were confirmed to have appendicitis, whether it be inflamed or perforated, shown in Table 6. From this data, men undergoing appendicectomy for acute appendicitis were more likely than women to indeed have appendicitis $\left(72.28 \%\right.$ vs $\left.51.09 \%, \chi^{2}=85.0, \mathrm{p}<0.01\right)$. This higher rate of misdiagnosis among women was noted by several authors, who emphasised the need to consider and exclude other pathology in women due to the potential of other mimicking conditions ${ }^{18,39} 29$.

Table 6. Appendicitis by gender

\begin{tabular}{cccccc} 
& & \multicolumn{2}{c}{ Total } & \multicolumn{2}{c}{ Appendicitis } \\
\hline & Year & M & F & M & F \\
\hline Silber & 1953 & 57 & 50 & 40 & 20 \\
Spitz & 1969 & 348 & 318 & 274 & 182 \\
Levy & 1997 & 143 & 69 & 131 & 37 \\
Muthuphei & 1998 & 258 & 150 & 190 & 78 \\
Rogers & 2008 & 204 & 196 & 95 & 83 \\
\hline Totals & & 1010 & 783 & 730 & 400 \\
\hline
\end{tabular}

Four studies provided gender breakdowns for those who were found to have perforated appendicitis, shown in Table 7. Men who underwent appendicectomy for acute appendicitis were more likely to have perforated than women $\left(26.43 \%\right.$ vs $\left.21.24 \%, \chi^{2}=4.5, p=0.034\right)$, which is consistent with the general literature ${ }^{7}$. 
Table 7. Ruptured appendices by gender

\begin{tabular}{cccccc} 
& & \multicolumn{2}{c}{ Total } & \multicolumn{2}{c}{ Rupture } \\
\hline & Year & M & F & M & F \\
\hline Levy & 1997 & 143 & 69 & 35 & 11 \\
Muthuphei & 1998 & 258 & 150 & 50 & 21 \\
Rogers & 2008 & 204 & 196 & 60 & 43 \\
Chamisa & 2009 & 254 & 70 & 82 & 28 \\
\hline Totals & & 859 & 485 & 227 & 103 \\
\hline
\end{tabular}

\section{Health systems and quality metrics}

Recent studies have explored the role of the health system in providing adequate surgical care for South Africans, particularly in rural settings. As greater awareness has risen regarding inequality in surgical care, the Department of Health guidelines for which surgical services should be offered at the district level can be found in the District Hospital Service Package (DHSP) ${ }^{40}$.

However, rural district hospitals have been found to be performing very few appendicectomies, laparotomies and other general surgery procedures which are listed in the DHSP $^{41}$. This was partially due to the fact that the underlying pathology of an acute abdomen is often diagnosed intraoperatively, with some conditions treatable at district hospitals and others requiring transfer to higher level of care. Due to this uncertainty, medical officers have often opted to transfer patients to regional hospitals rather than potentially embark on cases which are considered too difficult for the district hospital level.

In Kwazulu-Natal, a surgical outreach programme was initiated by the Department of Health in an effort to deliver surgical care and training to district hospitals. In their review of 12 years of activity in rural Kwazulu-Natal, Clarke et al (2014) found that "there remains a significant gap between the range of surgeries the WHO believes should be performed in a district hospital and what is actually delivered" ${ }^{42}$. 


\section{$\underline{\text { Discussion }}$}

Following Erasmus' audit in 1939, appendicitis research in South Africa has addressed the issues of differences in incidence, perforation and morbidity associated with the disease. Appendicitis incidence among white South Africans was comparable to incidence rates in developed countries, whereas the incidence among black South Africans was significantly lower. Perforation rates, however, were high in South Africa and were associated with delays in seeking medical care. Nearly all deaths recorded among appendicectomy patients were attributable to perforation and generalised peritonitis. Regarding gender differences, women undergoing appendicectomy were more likely to have a negative operation than men, but men were more likely to have more serious disease.

Generally speaking, the appendicitis trends observed here were consistent with those found in comparable settings. The perforation rate of $36.1 \%$ was consistent with experiences in other African countries ${ }^{43}$. Incidence rates were overall much lower than in developed countries, with slight increases as urbanisation had also increased.

However, despite the number of studies which have been performed over the last century, several notable gaps in the literature remain.

The body of literature for appendicitis in South Africa is skewed toward black populations utilising public health services, visibly lacking studies on white patients and those in the private sector. White South Africans have largely been assumed to behave similarly to white populations in developed countries, an oversimplification which fails to address cultural, environmental and social factors which are unique to this country. Research efforts focused on the public sector and do not capture the population which choose to utilise private health services, a group which conceivably does not face the same socioeconomic constraints as public sector patients which lead to delayed presentation and subsequent perforation. This 
omission may contribute to the demonstrably poor outcomes which have characterised South African audits to date, but the degree of this potential effect is unknown.

Perhaps related to this skew is the unusually long times to presentation noted for South African patients. As shown in the reviewed studies, South Africans presented to the hospital notably later than patients in developed settings. Numerous reasons and influences have been suggested by the investigators of the audits, but more comprehensive research of the influential factors for delay is lacking. There are studies exploring attitudes toward hospitals and deterrents for seeking medical care for South Africans in general ${ }^{44}$, but relating to surgical patients specifically, the reasons for delaying medical care need to be more fully explored.

The surgical approach for appendicitis has been mentioned in several studies, with a very small proportion of laparoscopic approaches used in Kong et $a l^{26}$. From the current literature, the understanding would follow that the vast majority of appendicectomies performed in South Africa are via an open incision rather than a laparoscopic approach. Surgeons have increasingly recognised the importance of laparoscopic surgery, but generally public hospitals are not uniformly able to routinely offer them ${ }^{45}$.

One significant reason underlying this is the prohibitive costs of laparoscopic equipment. However, laparoscopic appendicectomy has been shown in some settings to not only provide equally safe and effective surgical treatment as open surgery, but also at comparable economic costs ${ }^{46}$. When considering the costs of either approach, post-surgical hospital care and productivity losses need to be factored to gain a full understanding of economic costs. Thus, research comparing laparoscopic and open approaches in South Africa is needed, including measurements of outcomes, length of hospital stay and effects on productivity. 
Given that many medical officers at district hospitals may not feel comfortable performing laparotomies and appendicectomies, rural patients seeking medical care at these hospitals may in fact have their care delayed and unduly suffer as a consequence. Further research is needed to understand how surgical services at the district hospital can be strengthened, thus offloading patient volume from regional centres and shortening delays to surgery for surgical patients. In addition to improving health outcomes for these patients, the cost burden on the health system would be expected to decrease as well if patients receive earlier treatment ${ }^{47}$.

The findings in this review, along with some notable gaps in the literature, express the need for further research investigating appendicitis in the private sector, understanding why delays in care occur, estimating the prevalence and outcomes of laparoscopic surgery, and strengthening surgical services at the district hospital. 


\section{$\underline{\text { References }}$}

1. Saidi HS, Adwok JA. Acute appendicitis: an overview. East Afr Med J. Mar 2000;77(3):152-156.

2. Berry J, Jr., Malt RA. Appendicitis near its centenary. Ann Surg. Nov 1984;200(5):567-575.

3. Carr NJ. The pathology of acute appendicitis. Ann Diagn Pathol. Feb 2000;4(1):4658.

4. Walker AR, Segal I. Appendicitis: an African perspective. $J$ R Soc Med. Nov 1995;88(11):616-619.

5. Rogers AD, Hampton MI, Bunting M, Atherstone AK. Audit of appendicectomies at Frere Hospital, Eastern Cape. S Afr J Surg. Aug 2008;46(3):74-77.

6. Gadomski A, Jenkins P. Ruptured appendicitis among children as an indicator of access to care. Health Serv Res. Apr 2001;36(1 Pt 1):129-142.

7. Addiss DG, Shaffer N, Fowler BS, Tauxe RV. The epidemiology of appendicitis and appendectomy in the United States. Am J Epidemiol. Nov 1990;132(5):910-925.

8. Braveman P, Schaaf VM, Egerter S, Bennett T, Schecter W. Insurance-related differences in the risk of ruptured appendix. N Engl J Med. Aug 18 1994;331(7):444449.

9. Herrod HG, Chang CF. Potentially avoidable pediatric hospitalizations as defined by the Agency for Healthcare Research and Quality: what do they tell us about disparities in child health? Clin Pediatr (Phila). Mar 2008;47(2):128-136. 
10. Pieracci FM, Eachempati SR, Barie PS, Callahan MA. Insurance status, but not race, predicts perforation in adult patients with acute appendicitis. Journal of the American College of Surgeons. Sep 2007;205(3):445-452.

11. Smink DS, Fishman SJ, Kleinman K, Finkelstein JA. Effects of race, insurance status, and hospital volume on perforated appendicitis in children. Pediatrics. Apr 2005;115(4):920-925.

12. Guagliardo MF, Teach SJ, Huang ZJ, Chamberlain JM, Joseph JG. Racial and ethnic disparities in pediatric appendicitis rupture rate. Acad Emerg Med. Nov 2003;10(11):1218-1227.

13. Tsay JH, Lee CH, Hsu YJ, et al. Disparities in appendicitis rupture rate among mentally ill patients. BMC Public Health. 2007;7:331.

14. Hansson J, Korner U, Ludwigs K, Johnsson E, Jonsson C, Lundholm K. Antibiotics as first-line therapy for acute appendicitis: evidence for a change in clinical practice. World J Surg. Sep 2012;36(9):2028-2036.

15. Wilms IM, de Hoog DE, de Visser DC, Janzing HM. Appendectomy versus antibiotic treatment for acute appendicitis. Cochrane Database Syst Rev. Nov 9 2011(11):CD008359.

16. Lee SL, Yaghoubian A, Stark R, Shekherdimian S. Equal access to healthcare does not eliminate disparities in the management of adults with appendicitis. J Surg Res. Oct 2011;170(2):209-213.

17. Erasmus JPF. The incidence of appendicitis in the Bantu. S Afr Med J. 1939;13:601607. 
18. Silber W. Appendicectomy; a survey of 200 cases. S Afr Med J. Feb 28 1953;27(9):187-190.

19. Movsowitz L. Some observations on appendicitis in general practice in Upington. $S$ Afr Med J. Sep 2 1967;41(33):823-826.

20. Mayo $\mathrm{CH}$. THe appendix in relation to, or as the cause of, other abdominal diseases. Journal of the American Medical Association. 1924;83(8):592-593.

21. Burkitt DP, Walker AR, Painter NS. Effect of dietary fibre on stools and the transittimes, and its role in the causation of disease. Lancet. Dec 30 1972;2(7792):14081412.

22. Walker AR, Walker BF. Appendectomy in South African inter-ethnic school pupils. Am J Gastroenterol. Mar 1987;82(3):219-222.

23. Moore SW, Robbs JV. Acute appendicitis in the Zulu--an emerging disease? S Afr Med J. Apr 28 1979;55(18):700.

24. Griffiths ML. A comparison of admissions to a semirural hospital between the years 1959/1960 and 1977/1978. S Afr Med J. Jun 27 1981;59(27):983-986.

25. Segal I, Paterson A, Walker AR. Characteristics and occurrence of appendicitis in the black population in Johannesburg, South Africa. J Clin Gastroenterol. Oct 1986;8(5):530-533.

26. Kong VY, Bulajic B, Allorto NL, Handley J, Clarke DL. Acute appendicitis in a developing country. World J Surg. Sep 2012;36(9):2068-2073. 
27. Jones BA, Demetriades D, Segal I, Burkitt DP. The prevalence of appendiceal fecaliths in patients with and without appendicitis. A comparative study from Canada and South Africa. Ann Surg. Jul 1985;202(1):80-82.

28. Brink CF, Prinsloo H, van der Poel JS. [The seasonal incidence of acute appendicitis]. S Afr Med J. Aug 3 1985;68(3):156-158.

29. Levy RD, Degiannis E, Kantarovsky A, Maberti PM, Wells M, Hatzitheofilou C. Audit of acute appendicitis in a black South African population. S Afr J Surg. Nov 1997;35(4):198-202.

30. Boyce FF, McFetridge EM. The essential clinical considerations of acute appendicitis. Internat. S. Digest. 1936;22(Oct.):195-213.

31. Chamisa I. A clinicopathological review of 324 appendices removed for acute appendicitis in Durban, South Africa: a retrospective analysis. Ann R Coll Surg Engl. Nov 2009;91(8):688-692.

32. Walker AR, Walker BF, Manetsi B, Tsotetsi NG, Segal I. Appendicitis in Soweto, South Africa: traditional healers and hospitalization. J R Soc Health. Dec 1989;109(6):190-192.

33. Fulton J, Lazarus C. Acute appendicitis among black South Africans. S Afr J Surg. Dec 1995;33(4):165-166.

34. Madiba TE, Haffejee AA, Mbete DL, Chaithram H, John J. Appendicitis among African patients at King Edward VIII Hospital, Durban, South Africa: a review. East Afr Med J. Feb 1998;75(2):81-84. 
35. Kong VY, Van der Linde S, Aldous C, Handley JJ, Clarke DL. Quantifying the disparity in outcome between urban and rural patients with acute appendicitis in South Africa. S Afr Med J. Jul 29 2013;103(10):742-745.

36. Nel CJ, Theron EJ. [Appendicitis in the Black population]. S Afr Med J. Jun 2 1979;55(23):939-941.

37. Moore SW, Schneider J. Acute appendicitis in childhood: experience in a developing country. Pediatric Surgery International. 1995;10(2-3):71-75.

38. Muthuphei MN, Morwamoche P. The surgical pathology of the appendix in South African blacks. Cent Afr J Med. Jan 1998;44(1):9-11.

39. Spitz L. Acute appendicitis. An analysis of six hundred and sixty-six appendicectomies in adults 1959-1968. S Afr J Surg. 1969;7(3):129-137.

40. The Primary Healthcare Package for South Africa - a Set of Norms and Standards. Part 3: Norms and Standards for District Hospitals. Pretoria. Department of Health. 2002:

http://www.ruralrehab.co.za/uploads/3/0/9/0/3090989/norms_and_standards_district $\underline{\text { hospital.pdf }}$

41. Voss M, Duvenage R. Operative surgery at the district hospital. S Afr Med J. Jul 25 2011;101(8):521-522.

42. Clarke DL, Aldous C. Surgical outreach in rural South Africa: are we managing to impart surgical skills? S Afr Med J. Jul 2013;104(1):57-60.

43. Ohene-Yeboah M, Togbe B. An audit of appendicitis and appendicectomy in Kumasi, Ghana. West Afr J Med. Apr-Jun 2006;25(2):138-143. 
44. Harris B, Goudge J, Ataguba JE, et al. Inequities in access to health care in South Africa. J Public Health Policy. 2011;32 Suppl 1:S102-123.

45. Apostolou C, Panieri E. National survey of surgeons' attitudes to laparoscopic surgical training in South Africa. S Afr J Surg. Aug 2007;45(3):86, 88, 90-81.

46. Minutolo V, Licciardello A, Di Stefano B, Arena M, Arena G, Antonacci V. Outcomes and cost analysis of laparoscopic versus open appendectomy for treatment of acute appendicitis: 4-years experience in a district hospital. BMC Surg. Mar 19 2014;14(1):14.

47. Kong V, Aldous C, Handley J, Clarke D. The cost effectiveness of early management of acute appendicitis underlies the importance of curative surgical services to a primary healthcare programme. Ann R Coll Surg Engl. May 2013;95(4):280-284. 


\section{PART C: MANUSCRIPT}




\section{Acute appendicitis in the public and private sectors in Cape Town, South Africa}

Background: South Africa has a low incidence of acute appendicitis, but poor outcomes compared to developed countries. There is a lack of research on appendicitis in the private sector. This study aims to compare appendicitis in public and private hospitals to fully understand the nature of appendicitis in South Africa.

Methods: A prospective cohort study was conducted among 2 public and 3 private hospitals in the Cape Town metropole, from September 2013 to March 2014. Hospital records, operative notes and histology results were reviewed for patients undergoing appendicectomy for acute appendicitis. Patients were interviewed during their hospitalisation and followed up at monthly intervals until normal function was attained.

Results: There were 134 patients enrolled, with 73 in the public and 61 in the private sector. Education and employment were higher among private sector patients. Public sector patients had a higher rupture rate $(30.6 \%$ vs $13.2 \%, \mathrm{p}=0.023)$. Times to presentation were not statistically different between the two groups. Public sector patients had longer hospital stays (5.3 vs 2.9 days, $\mathrm{p}=0.036$ ) and longer return to work times (23.0 vs 12.1 days, $\mathrm{p}<0.0001)$. Although complication rates were similar, complications in public hospitals were more severe.

Discussion: Public sector patients with appendicitis have higher rupture rates, worse complications, and longer hospital stays than private sector patients. Private sector patients have rupture rates similar to developed nations. 


\section{Background}

Acute appendicitis is one of the commonest surgical emergencies, but appears to have a relatively lower incidence in Africa ${ }^{1}$. In its disease course, the appendix becomes inflamed and infected by intestinal bacteria, leading to swelling and eventual wall rupture if left untreated $^{2}$. If ruptured, the abdominal cavity is then susceptible to widespread infection, leading to sepsis and death. Patients with ruptured appendicitis have longer hospital stays, more complications, and higher mortality than patients who do not progress to rupture ${ }^{3}$. Given the consistent progression to perforation and potential health gains with early treatment, rates of rupture have been advocated as a public health measure of access to medical care ${ }^{4}$.

In South Africa, audits of appendicitis have consistently demonstrated higher perforation and complication rates compared to those in developed countries ${ }^{3,5-7}$. These have been attributed to longer delays of presentation to hospitals ${ }^{8}$, socioeconomic disadvantage ${ }^{9}$, and health system constraints ${ }^{3}$ common to South Africa and developing regions. South Africa has a two-tiered health system, with approximately $85 \%$ of the population using the public sector hospital services and the remaining $15 \%$ using a well-resourced private health system ${ }^{10}$. The current body of literature in South Africa has focused mostly on public sector facilities serving disadvantaged communities. There is a substantial population, however, who utilise private health facilities and who have not been included in previous appendicitis research ${ }^{11}$.

Therefore, the aim of this study was to compare patients with acute appendicitis in the public and private sectors in South Africa. More specifically, we sought to compare patient characteristics, perforation rates and postoperative recoveries between the two sectors. 


\section{$\underline{\text { Methods }}$}

All adults undergoing appendicectomy for presumed acute appendicitis from September 2013 to March 2014 were eligible for inclusion in this study. All patients were 18 years of age or older. The period for enrolment continued until sufficient numbers were obtained to adequately power both arms of the study. Patients undergoing incidental appendicectomy, or those treated conservatively, were excluded from this study.

Patients were enrolled from two public hospitals and three private hospitals in the Cape Town metropole. Of the public hospitals, one was a tertiary hospital and the other a regional hospital, both receiving patients referred from district hospitals in the region. The private sector patients were under the care of a group of surgeons who operated at three different hospitals, as well as other private surgeons in solo practice.

Patients were enrolled while hospitalised for appendicectomy by the same investigator. At that time, the patients were interviewed and their symptom course and journey from illness onset to the theatre documented. Hospital records were reviewed, including vital signs, laboratory investigations, histology, theatre records, and operative notes from the surgeons. Four weeks after discharge, a follow-up interview was conducted with patients either telephonically or in person, and their in-hospital postoperative course and recovery at home documented. If patients had not returned to work yet or resumed normal function, follow-up interviews were conducted at monthly intervals until normal function was reached.

\section{Sample size}

Epidemiologic studies in South Africa have estimated rates of rupture of the appendix to range from $34-57 \%$, compared to $16-19 \%$ in the U.S. ${ }^{3,5,7,12-14}$. Using averages from these 
figures, point estimates for rupture rates were estimated to be $47.3 \%$ and $21.7 \%$ in South Africa and the USA, respectively. We have hypothesised that rupture rates in the public sector in Cape Town would be similar to this South African figure, and that the rupture rate in the private sector would resemble that of the U.S. Using a level of significance $(\alpha)$ of 0.05 , and power of 0.80 , a sample size of 59 patients in each cohort was needed to compare rupture rates in the public and private sectors in Cape Town.

\section{Definitions}

Symptom onset was defined as when the patient first noted abdominal discomfort. Time to presentation was defined as the time from symptom onset to presentation at the final hospital at which appendicectomy was performed. Each clinic, emergency department, and hospital visited prior to reaching the final hospital was counted as a referral stop. Patients were asked to self-report race, and responses were categorised according to racial categories employed by the national census (Black African, Coloured, Indian or Asian, White, Other) ${ }^{15}$. Patients who declined to report race, identified with multiple racial categories, or identified with a different racial category were classified as "other". Race was included in this study to compare with previous South African studies hypothesising racial differences in appendicitis outcomes $^{6,16}$.

Operative findings were taken from the surgeon's operative notes and classified as one of the following: normal, acutely inflamed appendix without rupture, gangrenous appendicitis, or ruptured appendicitis. For histological classifications, perforation was classified as being perforated on macroscopic analysis. The diagnosis of acute appendicitis was made by the reviewing pathologist for each specimen. 
Return to work was calculated as the number of days from hospital discharge until returning to work. If a patient was unemployed, they were asked when they felt they would have been able to work a full day at their previous job, if they had been employed in the past, or resume normal daily activities. For full-time students, patients were asked when they were able to engage in a full-day of classes.

\section{Statistical analysis}

Exploratory analyses were conducted on demographic variables. Continuous variables were described using mean or median values, and categorical variables as percentages. Continuous variables were compared using the t-test for independent samples or Wilcoxon rank sum test for nonparametric data. Associations between categorical variables were conducted using either chi square analyses or Fisher's exact test, as appropriate. All analyses were conducted on Stata $12^{17}$.

\section{$\underline{\text { Results }}$}

\section{Demographics}

A total of 134 patients were enrolled in the study, with 73 from public hospitals and 61 from private hospitals. The average ages in both groups were similar (32.3 and 33.0 years, $\mathrm{p}=0.724)$. Gender splits within each cohort were also the same, with each cohort being split equally between males and females.

Racial demography differed significantly between the two cohorts, with private sector patients being predominantly white $(49.0 \%)$, and public sector patients being mostly coloured 
$(52.1 \%)$. Black patients were more likely to receive care in public hospitals than at private facilities $(82.8 \%$ vs $17.2 \%, \mathrm{p}=0.001)$.

Education levels also varied between the two cohorts. Most of the public sector patients did not study past secondary school (76.8\%), whereas most private sector patients studied in tertiary education and beyond $(68.8 \%)$. No public sector patients reached postgraduate education, compared to $26.2 \%$ of the private sector patients.

Table 1. Demographics

\begin{tabular}{|c|c|c|c|}
\hline & Public $(n=73)$ & Private $(\mathrm{n}=61)$ & p-value \\
\hline Age (mean, SD) & 32.3 years $( \pm 10.7)$ & 33.0 years $( \pm 13.8)$ & 0.724 \\
\hline Male & $37(50.68 \%)$ & $31(50.8 \%)$ & 0.988 \\
\hline Female & $36(49.3 \%)$ & $30(49.2 \%)$ & \\
\hline \multicolumn{4}{|l|}{ Race } \\
\hline Black African & $24(32.9 \%)$ & $5(8.2 \%)$ & $<0.001$ \\
\hline Coloured & $38(52.1 \%$ & $14(23.0 \%)$ & \\
\hline Indian or Asian & $0(0 \%)$ & $5(8.2 \%)$ & \\
\hline White & $4(5.5 \%)$ & $30(49.2 \%)$ & \\
\hline Other & $7(9.6 \%)$ & $7(11.5 \%)$ & \\
\hline \multicolumn{4}{|l|}{ Education } \\
\hline Primary & $5(6.9 \%)$ & $0(0 \%)$ & 0.001 \\
\hline Secondary & $51(69.9 \%)$ & $19(31.2 \%)$ & \\
\hline Partial Tertiary & $2(2.7 \%)$ & $3(4.9 \%)$ & \\
\hline Tertiary & $15(20.6 \%)$ & $23(37.7 \%)$ & \\
\hline Honours & $0(0 \%)$ & $8(13.1 \%)$ & \\
\hline Masters & $0(0 \%)$ & $6(9.8 \%)$ & \\
\hline Doctorate & $0(0 \%)$ & $2(3.3 \%)$ & \\
\hline \multicolumn{4}{|l|}{ Employment } \\
\hline Unemployed & $20(27.4 \%)$ & $5(8.2 \%)$ & 0.006 \\
\hline Employed & $44(60.3 \%)$ & $40(65.6 \%)$ & \\
\hline Full-time student & $9(12.3 \%)$ & $16(26.3 \%)$ & \\
\hline \multicolumn{4}{|l|}{ Medical aid } \\
\hline Yes & $3(4.1 \%)$ & $60(98.4 \%)$ & $<0.001$ \\
\hline No & $70(95.9 \%)$ & $1(1.6 \%)$ & \\
\hline
\end{tabular}


Public sector patients were more likely to be unemployed than private sector patients $(27.4 \%$ vs $8.2 \%$ ). Of the unemployed private sector patients, 3 were housewives with working husbands, 1 was retired, and the other was on lifelong disability. There were more full-time students in the private sector than the public (12.3\% public, $26.3 \%$ private). Nearly all private sector patients had medical insurance coverage $(98.4 \%)$, and the vast majority of public sector patients did not (95.9\%).

\section{Disease onset to hospital/presentation}

To seek access to medical care, an overwhelming $98.4 \%$ of private sector patients used private transport, compared to $57.5 \%$ of public sector patients. One private patient used public transportation (1.6\%), compared to $21.9 \%$ of public sector patients. Public sector patients were also more likely to use the ambulance services than private sector patients $(52.1 \%$ vs $4.9 \%)$.

Patients in both sectors took different routes to get to the hospital, but on average each had two stops before reaching the hospital. These stops included visits to a general practitioner, day hospital, private medi-clinic, or the emergency department. There was not a significant difference in times to presentation (56.2 vs 49.2 hours, $\mathrm{p}=0.360$ ).

When reporting symptoms, most reported abdominal pain localised to the right lower quadrant $(85.2 \%)$. Public sector patients were more likely to report nausea or vomiting, anorexia, or fever $(\mathrm{p}<0.05)$. Public sector patients were also more likely to report nausea or vomiting, anorexia, and fever than private patients. 
Table 2. Disease presentation

\begin{tabular}{|c|c|c|c|}
\hline & Public (n=73) & Private $(n=61)$ & $\mathrm{p}$-value \\
\hline Referral stops & $2.2( \pm 1.0)$ & $2.0( \pm 0.8)$ & 0.169 \\
\hline \multicolumn{4}{|l|}{ Transport } \\
\hline Private & $42(57.5 \%)$ & $60(98.4 \%)$ & $<0.001$ \\
\hline Public & $16(21.9 \%)$ & $1(1.6 \%)$ & $<0.001$ \\
\hline Ambulance & $38(52.1 \%)$ & $3(4.9 \%)$ & $<0.001$ \\
\hline Time to presentation & $56.2( \pm 70.4)$ & $49.2( \pm 59.3)$ & 0.360 \\
\hline \multicolumn{4}{|l|}{ Symptoms } \\
\hline$R L Q$ pain & $66(90.4 \%)$ & $49(80.3 \%)$ & 0.096 \\
\hline Nausea or vomiting & $62(84.9 \%)$ & $37(60.7 \%)$ & 0.001 \\
\hline Diarrhea & $12(16.4 \%)$ & $15(24.6 \%)$ & 0.241 \\
\hline Anorexia & $62(84.9 \%)$ & $43(70.5 \%)$ & 0.043 \\
\hline Fever & $42(57.5 \%)$ & $24(39.3 \%)$ & 0.036 \\
\hline \multicolumn{4}{|l|}{$\begin{array}{l}\text { Laboratory } \\
\text { investigations }\end{array}$} \\
\hline Temp & $36.8( \pm 1.0)$ & $36.8( \pm 0.7)$ & 0.861 \\
\hline Heart rate & $99.6( \pm 26.4)$ & $85.5( \pm 24.0)$ & 0.002 \\
\hline Systolic BP & $126.0( \pm 21.3)$ & $128.6( \pm 21.5)$ & 0.789 \\
\hline Diastolic BP & $76.6( \pm 13.7)$ & $72.8( \pm 16.0)$ & 0.030 \\
\hline Respiratory rate & $18.4( \pm 3.9)$ & $18.3( \pm 2.2)$ & 0.807 \\
\hline$W B C$ & $15.8( \pm 6.8)$ & $13.4( \pm 4.7)$ & 0.071 \\
\hline$H G B$ & $13.7( \pm 2.1)$ & $13.7( \pm 1.5)$ & 0.829 \\
\hline$P L T$ & $310.8( \pm 102.1)$ & $234.9( \pm 61.3)$ & 0.002 \\
\hline$C R P$ & $202.2( \pm 136.7)$ & $72.8( \pm 88.7)$ & $<0.001$ \\
\hline
\end{tabular}

\section{Operative Data}

Recorded anaesthetic times were greater for public hospitals than private (1.7 hours vs 1.1 hours, $\mathrm{p}<0.001)$. In the private sector, all but one of the appendicectomies were performed either laparoscopically or via a local incision (47.5\% and 50.8\%). The one private sector patient who underwent laparotomy for appendicectomy was found to have a ruptured appendix with several intraabdominal abscesses on CT imaging. 
In the public sector, laparoscopic approaches were used about half as often $(24.7 \%$ vs $47.5 \%$, $\mathrm{p}=0.006$ ). Nine additional operations were started laparoscopically but were converted to open procedures $(12.3 \%)$. These conversions were done as a result of finding purulent peritonitis or experiencing technical difficulty with proceeding laparoscopically.

Of the 53 open procedures done in the public sector, $45.3 \%$ were done through a local incision, $39.6 \%$ via laparotomy, $13.2 \%$ via lower midline incision, and one via Pfannestiel incision (the gynaecology service had started the procedure).

Surgeons reported more perforations in in the public cohort than the private cohort $(41.1 \% \mathrm{vs}$ $23.0 \%, \mathrm{p}=0.026)$. Normal appendices were uncommon in each group $-6.9 \%$ of public sector patients, $9.8 \%$ of private.

Table 3. Operative data

\begin{tabular}{|c|c|c|c|}
\hline & Public $(n=73)$ & Private $(n=61)$ & p-value \\
\hline $\begin{array}{l}\text { Anaesthetic times } \\
\text { (hours, sd) }\end{array}$ & $1.7( \pm 1.0)$ & $1.1( \pm 0.4)$ & $<0.001$ \\
\hline \multicolumn{4}{|l|}{ Open } \\
\hline Lanz & $24(33.8 \%)$ & $31(50.8 \%)$ & $<0.001$ \\
\hline Lower midline & $7(9.9 \%)$ & $0(0 \%)$ & \\
\hline Laparotomy & $21(29.6 \%)$ & $1(1.6 \%)$ & \\
\hline Pfannestiel & $1(1.4 \%)$ & $0(0 \%)$ & \\
\hline Laparoscopic & $18(24.7 \%)$ & $29(47.5 \%)$ & 0.006 \\
\hline Conversions & $9(12.3 \%)$ & $0(0 \%)$ & 0.003 \\
\hline \multicolumn{4}{|l|}{ Operative Findings } \\
\hline Normal appendix & $5(6.9 \%)$ & $6(9.8 \%)$ & 0.079 \\
\hline Acutely inflamed & $29(39.7 \%)$ & $36(59.0 \%)$ & \\
\hline Gangrenous & $9(12.3 \%)$ & $5(8.2 \%)$ & \\
\hline Perforated & $30(41.1 \%)$ & $14(23.0 \%)$ & \\
\hline
\end{tabular}




\section{Hospital course}

Patients in public hospitals had longer hospital stays than patients in private hospitals (5.3 vs 2.9 days, $\mathrm{p}=0.034)$. This difference held true when comparing public and private sector patients with similar histological findings (data not shown).

Intensive care was required for $9.6 \%$ of public sector patients, compared to $3.3 \%$ of private sector patients $(\mathrm{p}=0.134)$. Complication rates were similar between the two sectors, with overall complication rates of $30.1 \%$ for the public sector and $26.2 \%$ for the private $(\mathrm{p}=0.617)$. Wound sepsis rates were $19 \%$ for both sectors. One public sector patient required reoperation for early bowel obstruction. Of the three private patients requiring reoperation, one had developed early bowel obstruction and two developed intraabdominal abscesses.

There were two deaths observed, both in the public sector. The first patient had perforated appendicitis with generalised peritonitis, developed a large wound dehiscence and enterocutaneous fistula, and died 30 days after his operation. The second patient had purulent peritonitis and a neuroendocrine tumour, developed an enterocutaneous fistula and died 30 days after her operation.

Table 4. Hospital course and complications

\begin{tabular}{rccc}
\hline & Public $(\mathrm{n}=73)$ & Private $(\mathrm{n}=61)$ & p-value \\
\hline Length of stay $(\mathrm{sd})$ & $5.3( \pm 7.1)$ & $2.9( \pm 1.7)$ & 0.036 \\
ICU & $7(9.6 \%)$ & $2(3.3 \%)$ & 0.134 \\
Complications & & & \\
Wound sepsis & $14(30.1 \%)$ & $16(26.2 \%)$ & 0.617 \\
Pneumonia & $1(1.4 \%)$ & $12(19.7 \%)$ & 0.943 \\
Fistulae & $3(4.1 \%)$ & $1(1.6 \%)$ & 0.705 \\
Ileus & $5(6.9 \%)$ & $0(0 \%)$ & 0.159 \\
Other & $3(4.1 \%)$ & $0(0 \%)$ & 0.045 \\
Reoperation & $1(1.4 \%)$ & $2(3.3 \%)$ & 0.620 \\
Readmission & $6(8.2 \%)$ & $3(4.9 \%)$ & 0.245 \\
Death & $2(2.7 \%)$ & $3(4.9 \%)$ & 0.344 \\
& & $0(0 \%)$ & 0.295 \\
\hline
\end{tabular}




\section{Histology}

The histology results are shown in Table 5. Public sector patients had a normal appendix on pathologic review at a similar rate as private patients $(13.9 \%$ vs $5.7 \%, \mathrm{p}=0.076)$. The perforation rate on histology for public sector patients was significantly higher than that for private patients $(30.6 \%$ vs $13.2 \%, \mathrm{p}=0.023)$, with an overall perforation rate for both cohorts of $24.0 \%$.

There were 14 patients with abnormal histology, but not appendicitis. Four were diagnosed with acute peritonitis, three with acute serositis, three with fibrous obliteration, two with early focal appendicitis, one with submucosal fibrosis, and one with a large neuroendocrine tumour.

Table 5. Histology results

\begin{tabular}{lccc}
\hline & Public $(\mathrm{n}=72)$ & Private $(\mathrm{n}=53)$ & Total $(\mathrm{n}=125)$ \\
\hline Normal & $10(13.9 \%)$ & $3(5.7 \%)$ & $13(10.4 \%)$ \\
Acute & $23(31.9 \%)$ & $32(60.4 \%)$ & $55(44.0 \%)$ \\
Gangrenous & $7(9.7 \%)$ & $7(13.2 \%)$ & $14(11.2 \%)$ \\
Perforated & $22(30.6 \%)$ & $7(13.2 \%)$ & $29(23.2 \%)$ \\
$\begin{array}{l}\text { Abnormal, not } \\
\text { appendicitis }\end{array}$ & $10(13.9 \%)$ & $4(7.6 \%)$ & $14(11.2 \%)$ \\
\hline
\end{tabular}

\section{Discharge \& Home Recovery}

Public sector patients took significantly longer to return to work than private sector patients, averaging 23.0 days versus 12.1 days $(\mathrm{p}<0.0001)$. This difference held true when performing subgroup analysis of patients with the same pathologic grade of appendicitis (Table 6). Additionally, public sector patients consistently had longer times to return to work than private patients when comparing only those with laparoscopic surgeries, open surgeries, or employment status (data not shown). 
Table 6. Return to work by histologic diagnosis

\begin{tabular}{llllc}
\hline & Public $(\mathrm{n}=63)$ & Private $(\mathrm{n}=54)$ & Total $(\mathrm{n}=117)$ & $\mathrm{p}$-value \\
\hline Acute $(\mathrm{sd})$ & $22.1( \pm 16.5)$ & $12.6( \pm 8.3)$ & $16.6( \pm 13.2)$ & 0.004 \\
Gangrenous (sd) & $15.4( \pm 10.6)$ & $10.9( \pm 5.8)$ & $13.6( \pm 8.6)$ & 0.335 \\
Perforated (sd) & $31.1( \pm 36.7)$ & $11.0( \pm 8.4)$ & $25.5( \pm 32.5)$ & 0.008 \\
& & & & \\
& $23.0( \pm 23.2)$ & $12.1( \pm 7.6)$ & $17.9( \pm 18.0)$ & $<0.0001$ \\
\hline
\end{tabular}

\section{$\underline{\text { Discussion }}$}

The presentation and outcomes of acute appendicitis differ between African and Western nations. Incidence rates of appendicitis among Africans have been estimated to be much lower than among Westerners ${ }^{18}$, but with higher rupture and complication rates ${ }^{3,13}$. In the South African literature, poorer outcomes have been attributed to socioeconomic disadvantage ${ }^{7}$, health system weaknesses ${ }^{3}$, poor access to care ${ }^{8}$, and delayed presentation to the hospital ${ }^{5}$. The majority of South Africans utilise public hospital services, but a relatively wealthy minority utilise private facilities ${ }^{10}$. Appendicitis in the public sector has been widely studied, whereas outcomes in the private sector have yet to be explored.

Age trends in this study were consistent with the general literature, with the peak incidence in patients in the second and third decade of life $\mathrm{e}^{13,18,19}$. While several audits have found a male skew in appendicectomy operations ${ }^{5-8,20,21}$, our study had an even gender split in both public and private cohorts. Negative appendicectomies have been reported to be more common among women, due to gynaecologic conditions which mimic appendicitis ${ }^{22}$. In our study, women trended toward higher rates of negative appendicectomies than men, although this was not statistically significant $(36.4 \%$ vs $25.0 \%$, $\mathrm{p}=0.154)$.

Not surprisingly, public and private sector patients in our study differed greatly in the racial demography, education level, employment status and access to medical insurance. These 
differences emphasise social and economic inequalities persistent in healthcare, such that wealthier patients are more likely to afford and access private health services ${ }^{23}$.

The public sector histological perforation rate of $31 \%$ was significantly higher than the $15 \%$ perforation rate in the private sector. This perforation rate in the public sector cohort falls in the $17-57 \%$ range estimated from past appendicitis audits in South African public hospitals, 9,20,21. The highest of these estimates came from studies which used operative findings as the basis for appendicitis classification ${ }^{3,7}$, rather than histological findings, which were used in this study to define perforation. There was a tendency for surgeons to overdiagnose perforation in the operating theatre compared to histological diagnoses in this study, a trend consistent with a previous study in Durban ${ }^{5}$.

The private sector perforation rate compares favourably with estimates in developed countries $^{12,13}$. This finding supports the presumption that private sector patients do not share the same factors that put disadvantaged South Africans at risk for perforation. The bulk of literature on appendicitis in South Africa has been limited to black patients in public

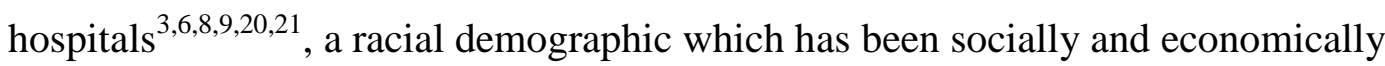
disadvantaged throughout the country's history ${ }^{24}$. This study provides valuable insight into a racially diverse cohort of patients, showing that while economic advantage remains largely adherent to racial divisions, these divisions are becoming increasingly blurred. The starkly different perforation rates between the two sectors reinforce the notion that perforation risks are not inherently racial in nature, as has been suggested in the past ${ }^{6,16}$, but instead related to social and economic factors.

Delays in presentation to the hospital are associated with increased perforation risk $^{25-27}$. In this study, public sector patients on average had longer presentation times than private patients, although this was not statistically significant. Within each histological class of 
appendicitis, there were no differences in presentation delays between public and private sector patients. However, when analysing both cohorts together, patients with perforated appendicitis had longer delays in presentation compared to patients without perforation (86.8 vs 43.3 hours, $\mathrm{p}<0.001)$.

Despite differing perforation rates, complication rates were comparable between the two sectors, with no significant difference found. Taken at face value, this may suggest similar severity of disease between the two groups. However, while the complications rates may themselves be similar, the complications in the public sector were arguably more severe in nature. For example, wound sepsis occurred in $19 \%$ of patients in both sectors, requiring antibiotics and in many cases, opening the surgical wound and allowing closure by secondary intent. While nearly all of the private patients with wound sepsis had small Lanz or laparoscopic incisions $(91.6 \%)$, over half of the public patients with wound sepsis had to manage open laparotomy incisions (57.1\%). Most of these patients lacked resources or assistance to dress their wounds at home, requiring repeated visits to day hospitals for dressing changes that often took several hours per visit.

Enterocutaneous fistulae were infrequent but highly morbid complications, and only occurred in the public sector cohort. Two of the three patients died approximately a month after their operations and were hospitalised up to their deaths. The third required parenteral nutrition, multiple readmissions, and specialised nursing care until the fistula closed six months after his operation.

The need for intensive care was not statistically different between the two cohorts, but there were notable differences between the public and private sector patients who required ICU admission. All of the public sector patients requiring intensive care were admitted to the ICU because of overwhelming sepsis resulting from their appendicitis. The two private sector 
patients admitted to the ICU required close monitoring for conditions unrelated to appendicitis- one developed hallucinations and severe anxiety from medications, and the other required tight glycaemic control for Type I diabetes. Thus, while ICU admissions did not vary significantly between the two cohorts, the underlying reasons for admission suggested a greater severity of disease in the public sector.

Patients in the public sector had higher heart rates and diastolic blood pressures than private sector patients. When taking their higher white blood cell counts, platelets, and C-reactive protein into account, public patients were observed to be in more acute distress than private patients.

Public sector patients had longer hospital stays than private patients, even when controlling for histological and operative diagnosis. A likely contributory factor is the pressure felt by private patients to recover quickly and minimise hospital stays, thereby avoiding large hospital fees and charges. Unlike those in the private sector, patients in the public sector cohort rarely cited this financial pressure as a motivation for recovery.

Public sector patients also took longer to return to work or normal activity than private sector patients, even when controlling for severity of disease, operative approach, and employment status. The reasons underpinning this difference are unclear from this study, but conceivably relate to a patient's home environment, support structures, type of employment, and motivation for recovery. Several patients held jobs which called for heavy physical activity, whereas others worked in sedentary office settings, meaning that work types heavily influence when a patient can return to work.

Surgical approaches have been discussed in recent studies, with very low rates of laparoscopy being utilised in public sector hospitals for appendicectomy ${ }^{7}$. In this study, appendicectomies were performed laparoscopically in a quarter of public hospital patients, and almost half of 
private patients. The decision to proceed with laparoscopy versus an open approach is influenced by a number of factors, including surgeon comfort, availability of equipment and support staff, patient characteristics, and issues pertaining to medical aid reimbursement. A number of private sector patients elected an open operation due to the potential that laparoscopy would not be adequately reimbursed by their medical aid.

Overall, the findings of this study reinforce the existing literature on appendicitis in South Africa, while raising some important questions. Appendicitis outcomes in South Africa have often been compared to those in Western countries in an effort to highlight the unique health system challenges which are faced here. However, there has been little information available on private sector patients with appendicitis. This study confirms the hypothesis that private sector patients with appendicitis have similar outcomes and disease presentation as patients in developed nations.

Therefore, it can confidently be stated that significant healthcare disparities in treating appendicitis exist not only between South Africa and Western nations, but also within the country itself. Furthermore, the disparities found in this study more or less follow socioeconomic divisions rather than racial lines, effectively arguing that high perforation rates in South Africa may largely be attributable to economic and system factors rather than ethnic factors.

From this study, important questions are raised about public health facilities, patients who access them, and the interface between the two. Understanding the decision-making process for public patients seeking urgent surgical care, as well as their experiences as patients in the health system, will enable health managers and policymakers to identify opportunities for system strengthening and ultimately improve patient outcomes. Analysis of the private sector may also shed light onto how outcomes may be improved in public hospitals. Ultimately, 
this study has shown that good appendicitis outcomes do exist in South Africa, providing hope for change in communities where this currently is not the case.

\section{Conclusions}

South African patients undergoing appendicectomy for acute appendicitis in the public sector have higher perforation rates, worse complications and more severe disease than patients in the private sector. This disparity likely stems from a combination of social and economic differences that characterise the patient populations that are served in each sector. Hospital stays and recovery at home are longer for public sector patients, even when controlling for disease severity and surgical approach. As a whole, patients with perforation had delayed coming to hospital longer than patients with non-perforated appendicitis, although the reasons underlying these delays are unclear. 


\section{$\underline{\text { References }}$}

1. Walker AR, Richardson BD, Walker BF, Woolford A. Appendicitis, fibre intake and bowel behaviour in ethnic groups in South Africa. Postgraduate medical journal. Apr $1973 ; 49(570): 243-249$.

2. Berry J, Jr., Malt RA. Appendicitis near its centenary. Ann Surg. Nov 1984;200(5):567-575.

3. Rogers AD, Hampton MI, Bunting M, Atherstone AK. Audit of appendicectomies at Frere Hospital, Eastern Cape. S Afr J Surg. Aug 2008;46(3):74-77.

4. Gadomski A, Jenkins P. Ruptured appendicitis among children as an indicator of access to care. Health Serv Res. Apr 2001;36(1 Pt 1):129-142.

5. Chamisa I. A clinicopathological review of 324 appendices removed for acute appendicitis in Durban, South Africa: a retrospective analysis. Ann R Coll Surg Engl. Nov 2009;91(8):688-692.

6. Madiba TE, Haffejee AA, Mbete DL, Chaithram H, John J. Appendicitis among African patients at King Edward VIII Hospital, Durban, South Africa: a review. East Afr Med J. Feb 1998;75(2):81-84.

7. Kong VY, Bulajic B, Allorto NL, Handley J, Clarke DL. Acute appendicitis in a developing country. World J Surg. Sep;36(9):2068-2073.

8. Levy RD, Degiannis E, Kantarovsky A, Maberti PM, Wells M, Hatzitheofilou C. Audit of acute appendicitis in a black South African population. S Afr J Surg. Nov 1997;35(4):198-202. 
9. Fulton J, Lazarus C. Acute appendicitis among black South Africans. S Afr J Surg. Dec 1995;33(4):165-166.

10. McIntyre D TM, Nkosi M, Mutyambizi V, Castillo-Riquelme M, Gilson L, Erasmus E, Goudge J. A critical analysis of the current South African health system. Health Economics Unit, University of Cape Town and Centre for Health Policy, University of the Witwatersrand. 2007.

11. Wadee H GL, Thiede M, Okorafor O, McIntyre D. Health care equity in South Africa and the public/private mix. United Nations Research Institute for Social Development (UNRISD). 2003 [cited 2014 Mar 28](Available from: www.unrisd.org).

12. Bickell NA, Aufses AH, Jr., Rojas M, Bodian C. How time affects the risk of rupture in appendicitis. Journal of the American College of Surgeons. Mar 2006;202(3):401406.

13. Addiss DG, Shaffer N, Fowler BS, Tauxe RV. The epidemiology of appendicitis and appendectomy in the United States. Am J Epidemiol. Nov 1990;132(5):910-925.

14. Papandria D, Goldstein SD, Rhee D, et al. Risk of perforation increases with delay in recognition and surgery for acute appendicitis. The Journal of surgical research. Oct 2013;184(2):723-729.

15. Statistics South Africa. Census 2011: Census in brief. Pretoria 2012. Report No. 0301-41. [cited 2014 Mar 28](Available from: www.statssa.gov.za/Census2011/Products/Census_2011_Census_in_brief.pdf)

16. Erasmus JPF. The incidence of appendicitis in the Bantu. S Afr Med J. 1939;13:601607. 
17. StataCorp. Stata Statistical Software: Release 13. College Station, TX: StataCorp LP; 2013.

18. Walker AR, Segal I. Appendicitis: an African perspective. J R Soc Med. Nov 1995;88(11):616-619.

19. Saidi HS, Adwok JA. Acute appendicitis: an overview. East Afr Med J. Mar 2000;77(3):152-156.

20. Muthuphei MN, Morwamoche P. The surgical pathology of the appendix in South African blacks. Cent Afr J Med. Jan 1998;44(1):9-11.

21. Nel CJ, Theron EJ. [Appendicitis in the Black population]. S Afr Med J. Jun 2 1979;55(23):939-941.

22. Spitz L. Acute appendicitis. An analysis of six hundred and sixty-six appendicectomies in adults 1959-1968. S Afr J Surg. 1969;7(3):129-137.

23. Harris B, Goudge J, Ataguba JE, et al. Inequities in access to health care in South Africa. J Public Health Policy.32 Suppl 1:S102-123.

24. Coovadia H, Jewkes R, Barron P, Sanders D, McIntyre D. The health and health system of South Africa: historical roots of current public health challenges. Lancet. Sep 5 2009;374(9692):817-834.

25. Eldar S, Nash E, Sabo E, et al. Delay of surgery in acute appendicitis. American journal of surgery. Mar 1997;173(3):194-198.

26. Bickell NA, Aufses AHJ, Rojas M, Bodian C. How time affects the risk of rupture in appendicitis. Journal of the American College of Surgeons. 2006;202:401. 
27. Kearney D, Cahill RA, O'Brien E, Kirwan WO, Redmond HP. Influence of delays on perforation risk in adults with acute appendicitis. Diseases of the colon and rectum. Dec 2008;51(12):1823-1827. 
APPENDICES 


\section{Appendix A: Data Collection Sheet}

Study \#:

Journey of care study for appendicectomy patients in the private and public sectors of Cape Town

\section{Demographics}

\begin{tabular}{|c|c|c|c|c|c|}
\hline Name (Last, First) & MRN & $\mathrm{DOB}(m m / d d / y y)$ & Sex & Admit date & Admit time (triage) \\
\hline Address & Employment & Race & Med aid $(\mathrm{Y} / \mathrm{N})$ & Preferred language & \\
\hline
\end{tabular}

\section{Presentation}

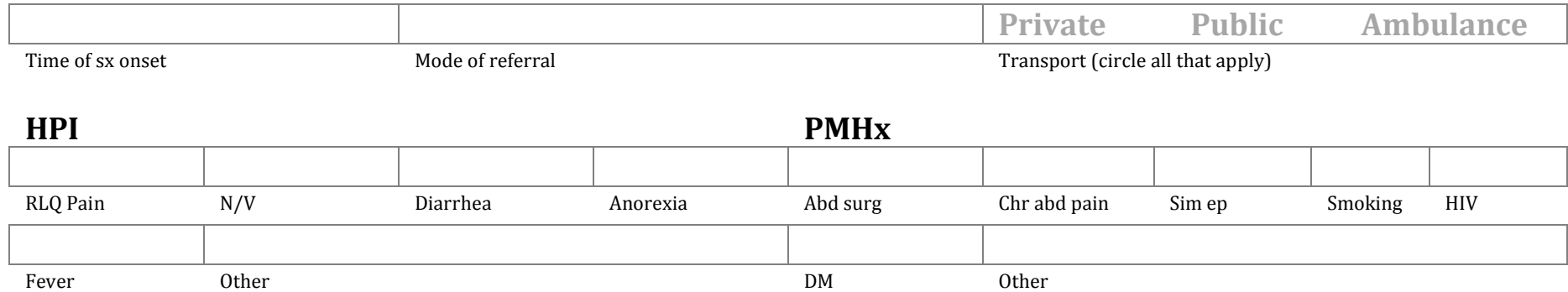

VS \& PE (VS @ initial presentation, PE by surgeon)

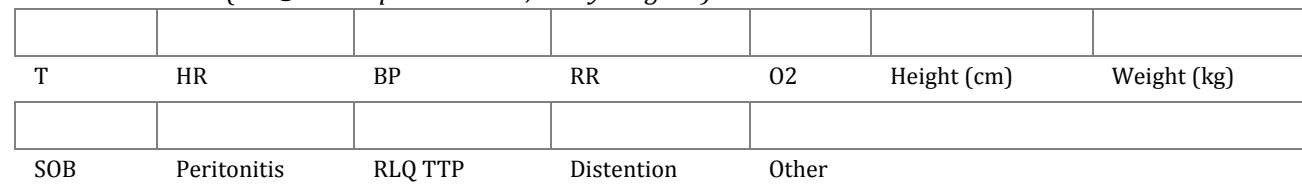
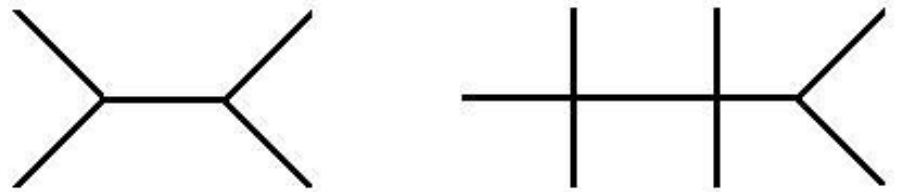

Albumin:

CRP:

Other:

Operative Data

\begin{tabular}{|l|l|l|l|}
\hline & & & $\mathrm{Y} / \mathrm{N}$ \\
\hline \multicolumn{1}{|c|}{ OR date start } & OR finish & Preop abx \\
\hline & & \\
\hline Open/Lap & Incision & Op findings \\
\hline
\end{tabular}

\section{Postop}

\begin{tabular}{|l|l|l|l|}
\hline & & & \\
\hline D/c date $\quad$ Postop abx $\quad$ Abx duration $\quad$ Visitors
\end{tabular}

\section{Complications}

\section{Notes}

Delay? If so, why?

Treated well? With dignity?

For questions or concerns regarding the study, please contact Dr. Estin Yang (yngest001@myuct.ac.za) 


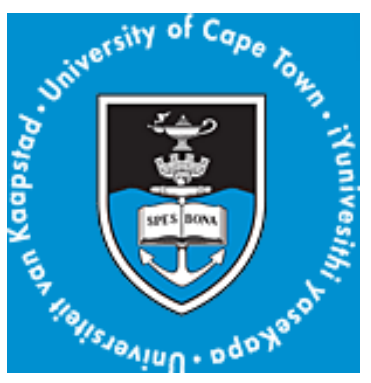

\title{
Appendix B: Patient Information Sheet and Consent Form
}

\author{
A prospective analysis of the journey of care for patients \\ undergoing appendicectomy in the public and private sectors in \\ Cape Town
}

Dr. Estin Yang

University of Cape Town

School of Public Health and Family Medicine

\begin{abstract}
About the Study
We are conducting research as part of the UCT School of Public Health to get a better understanding of how appendicitis affects South Africans in comparison to patients in other countries. In particular, we are collecting information on the details leading up to appendicectomy and the recovery process for patients. The study has been approved by the Human Research Ethics Committee at the University of Cape Town, which ensures that your safety and rights are respected throughout the entire research process.
\end{abstract}

In this study, we want to learn more about any delays you may have experienced in seeking care, any factors that affect your recovery at home after your appendicectomy, and the estimated recovery time from the surgery. We would like to conduct interviews with up to 120 patients who have undergone the same procedure. These interviews will be conducted in follow-up clinics across a range of medical facilities in the Cape Town area.

We have selected you for this interview because you have recently undergone appendicectomy, and because we feel that your experience can contribute to our understanding of what happens before and after surgery for South African patients.

Your participation in this study is entirely voluntary. Whether or not you decide to participate in this study will not affect your right to, or experience of, treatment and care at this or any other facility, now or at any point in the future.

Should you decide to participate in this study, you will be provided with a cash remuneration of $R 200$ for your time and travel expenses. This will be given upon completion of your final interview.

\section{If you decide to participate in this study:}

- Data from your patient charts and operative notes will be collected by our research team during your hospital stay: including demographic data, your medical history, physical exam, surgical procedure, and treatment received during your hospitalisation.

- When you return to the clinic for your follow-up appointment (typically 3-4 weeks after your hospital discharge), you will be asked to take part in a brief interview.

- In the interview, you will be asked a number of questions about your recovery, return to work, and your time of illness prior to hospitalization. If you do not want to answer any of the questions you may say so and we will move on to the next question. No-one else but the interviewer will be present at the interview site unless you would like someone else there

- The discussion will be recorded on a device to assist later in fully writing up the information.

- At any point throughout this study, you have the right to decide not to participate; there will not be any consequences.

- Your participation in this study will involve absolutely no risks to you. 


\title{
Confidentiality
}

No-one will be identified by name on the transcriptions of interview recordings, and all recordings will be destroyed upon completion of the research. All information from these interviews will be kept completely private and confidential, only to be viewed and used by the researchers on this project. We will not share individual information about you or other participants with anyone beyond a few people who are closely concerned with the research. All of our documents and recordings will be stored securely in password-protected computers in electronic format. Finally, knowledge gained from this research will only be shared in summary form, without revealing individuals' identities, with the medical community at large.

\section{Benefits of Participation}

Your participation in this study can help us improve understanding of appendicitis as it affects individuals economically, socially, and medically, for the benefit of all South Africans in the future. Our hope is that the information we collect through our research will help alleviate any barriers for those seeking medical care, as well as provide useful insights for caregivers and medical institutions.

\section{Questions?}

Please let us know if you have any questions. You are free to ask the interviewer any questions about this research, and also to contact the research team members at the email below.

\author{
Dr. Estin Yang \\ University of Cape Town \\ Email: appystudy@gmail.com \\ Faculty of Health Sciences Human Research Ethics Committee \\ Room E52-24 Groote Schuur Hospital Old Main Building \\ Observatory 7925 \\ Phone: (021) 4066492
}




\section{Participant Volunteer Declaration}

A prospective analysis of the journey of care for patients undergoing appendicectomy in the public and private sectors in Cape Town

University of Cape Town | School of Public Health and Family Medicine

$\mathrm{I}$, (name of participant) have understood that the purpose of the study is to gain a better understanding of appendicitis patients in South Africa. I have read the above information, or have had it explained to me. I have had the opportunity to ask questions about it, and any questions that I have asked have been answered to my satisfaction.

I declare that I am 18 years of age or older. I consent voluntarily to participate in the interviews.

I understand that I may be contacted by the research team by phone if necessary.

I also understand that I have the right to withdraw from this study at any time without my decision to withdraw in any way affecting my position as an attendee at this or any other health facility now or in the future.

PLEASE INDICATE YOUR CONSENT WITH YOUR SIGNATURE, OR A TICK IF PREFERRED.

Signature of Participant:

Date:

[tick optional]

Signature of Investigator:

Date:

Witness declaration if participant is unable to read and understand consent on his or her own:

I have observed the informed consent process and attest to the accuracy and apparent understanding of the participant:

Name of Witness:

Signature of Witness:

Date:

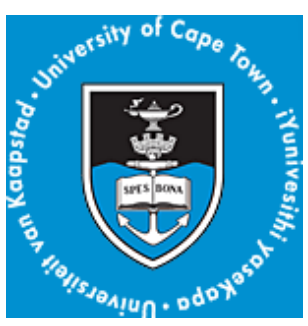




\title{
Appendix C: Letter of Approval from Research Ethics Committee
}

\section{UNIVERSITY OF CAPE TOWN}
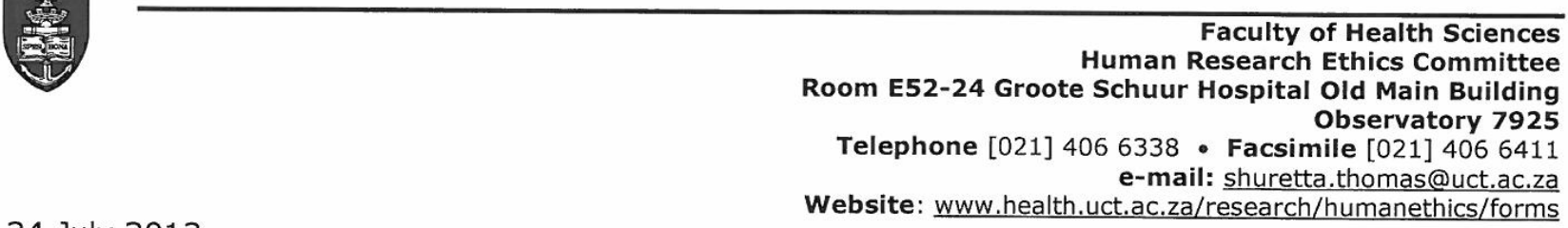

24 July 2013

Website: www.health.uct.ac.za/research/humanethics/forms

HREC REF: $319 / 2013$

\author{
Mr E Yang \\ c/o Dr D Kahn \\ Public Health \& Family Medicine \\ Falmouth Building
}

Dear Mr Yang

\section{PROJECT TITLE: A PROSPECTIVE ANALYSIS OF THE JOURNEY OF CARE FOR PATIENTS UNDERGOING APPENDICECTOMY IN THE PUBLIC AND PRIVATE SECTORS IN CAPE TOWN}

Thank you for responding to the Faculty of Health Sciences Human Research Ethics Committee in your letter dated $22^{\text {nd }}$ July 2013

It is a pleasure to inform you that the HREC has formally approved the above-mentioned study.

\section{Approval is granted for one year till the $30^{\text {th }}$ July 2014}

Please submit a progress form, using the standardised Annual Report Form if the study continues beyond the approval period. Please submit a Standard Closure form if the study is completed within the approval period.

(Forms can be found on our website: www.health.uct.ac.za/research/humanethics/forms)

Please note that the ongoing ethical conduct of the study remains the responsibility of the principal investigator.

Please quote the HREC. REF in all your correspondence.

Yours sincerely

$$
\text { TuBuges }
$$

\section{PROFESSOR M BLOCKMAN}

\section{CHAIRPERSON, FHS HUMAN ETHICS}

Federal Wide Assurance Number: FWA00001637.

Institutional Review Board (IRB) number: IRB00001938

This serves to confirm that the University of Cape Town Human Research Ethics Committee complies to the Ethics Standards for Clinical Research with a new drug in patients, based on the Medical

Research Council (MRC-SA), Food and Drug Administration (FDA-USA), International Convention on Harmonisation Good Clinical Practice (ICH GCP) and Declaration of Helsinki guidelines.

The Human Research Ethics Committee granting this approval is in compliance with the ICH Harmonised Tripartite Guidelines E6: Note for Guidance on Good Clinical Practice (CPMP/ICH/135/95) and FDA Code Federal Regulation Part 50, 56 and 312. 
Appendix D: Instructions for Authors (JAMA Surgery) 